\title{
Kidney transplant outcomes in HIV-positive patients: a systematic review and meta-analysis
}

\author{
Xin Zheng ${ }^{1,2}$, Lian Gong ${ }^{1,2}$, Wenrui Xue ${ }^{3}$, Song Zeng ${ }^{1,2}$, Yue Xu ${ }^{1,2}$, Yu Zhang ${ }^{3}$ and Xiaopeng $\mathrm{Hu}^{1,2^{*}}$
}

\begin{abstract}
Background: Kidney transplantation is now a viable alternative to dialysis in HIV-positive patients who achieve good immunovirological control with the currently available antiretroviral therapy regimens. This systematic review and meta-analysis investigate the published evidence of outcome and risk of kidney transplantation in HIV-positive patients following the PRISMA guidelines.

Methods: Searches of PubMed, the Cochrane Library and EMBASE identified 27 cohort studies and 1670 case series evaluating the survival of HIV-positive kidney transplant patients published between July 2003 and May 2018. The regimens for induction, maintenance therapy and highly active antiretroviral therapy, acute rejection, patient and graft survival, CD4 count and infectious complications were recorded. We evaluated the patient survival and graft survival at 1 and 3 years respectively, acute rejection rate and also other infectious complications by using a randomeffects analysis.
\end{abstract}

Results: At 1 year, patient survival was 0.97 ( $95 \% \mathrm{Cl} 0.95 ; 0.98)$, graft survival was 0.91 (95\% Cl 0.88; 0.94), acute rejection was 0.33 (95\% Cl 0.28; 0.38), and infectious complications was 0.41 (95\% Cl 0.34; 0.50), and at 3 years, patient survival was 0.94 ( $95 \% \mathrm{Cl} 0.90 ; 0.97)$ and graft survival was 0.81 ( $95 \% \mathrm{Cl} 0.74 ; 0.87)$.

Conclusions: With careful selection and evaluation, kidney transplantation can be performed with good outcomes in HIV-positive patients.

\section{Background}

Traditionally, human immunodeficiency virus (HIV)positive patients (HIV+) has not been considered to be good candidates for solid-organ transplantation for the poor prognosis of HIV patients. However, with the introduction of antiretroviral combination therapy (cART), the survival of HIV+ patients have been great improved. While the frequency of Acquired Immune Deficiency Syndrome (AIDS)-related events has consequently decreased, mortality due to organ failure has become a significant concern.

The initial attempts at kidney transplantation (KT) in HIV+ patients led to poor outcomes, but better results occurred with the availability of highly active antiretroviral therapy (HAART) $[1,2]$.

\footnotetext{
*Correspondence: xiaopeng_hu@sina.com

${ }^{2}$ Department of Urology, Beijing Chaoyang Hospital, Capital Medical

University, 8 Gongti Nanlu, Chaoyang District, Beijing, China

Full list of author information is available at the end of the article
}

In this scenario, KT started to be proposed as a treatment even as "standard-of-care" for end-stage renal disease (ESRD) in selected HIV+ patients [3].

A multicentre study in the USA found that the survival rates for HIV+ recipients fall between those reported for older KT recipients and for all recipients in the American national database [4].

Despite these encouraging results, many issues still need to be addressed. Among the more relevant are the elevated incidence of acute rejection (AR), lower patient survival (PS) and graft survival (GS), and the hurdles caused by the interaction of immunosuppressive and antiretroviral (ARV) drugs. We conducted a systemic review and meta-analysis to determine the effectiveness of KT in the presence of HIV. Specifically, we examined PS and GS, AR and infectious complications in HIV+ patients who have undergone KT. 


\section{Methods}

\section{Study design}

The study design of a systematic review and metaanalysis was chosen to define the published evidence of the effectiveness of KT in HIV+ patients. The study followed the Preferred Reporting Items for Systematic Reviews and Meta-Analysis (PRISMA) statement standards [5]. Our review was registered at the International Prospective Register of Systematic Reviews (PROSPERO CRD42018109178).

\section{Search strategy}

We searched the Medline (1966 to June 2018), EMBASE (1974 to June 2018), and Cochrane Controlled Trials Register databases to identify studies that referred to $\mathrm{KT}$ in HIV+ patients; we also searched the reference lists of the retrieved studies. The following search terms were used: $\mathrm{KT}, \mathrm{HIV}+$, AIDS. A combination of subject headings and keywords for KT, HAART, HIV+ recipient, allograft survival, antiretroviral therapy, donor selection, ESRD and immunosuppression was used for the literature search.

\section{Eligibility criteria}

Cohort studies and case-control studies were all eligible for inclusion if they reported outcomes of $\mathrm{KT}$ in HIV+ patients. Studies reporting outcomes shorter than 12 months post transplantation and transplantation occurring before HAART were introduced were excluded. Articles were independently assessed by 2 reviewers ( $\mathrm{X} \mathrm{Z}$ and WR X) according to the predetermined eligibility criteria. Any disagreement between reviewers was resolved by discussion with a third reviewer (XP H).

\section{Data extraction}

All data were extracted independently by 2 reviewers (X $\mathrm{Z}$ and WR X) onto a Microsoft Excel spreadsheet (XP Professional Edition; Microsoft Corp, Redmond, WA), and any discrepancies were resolved by consensus. The following information was collected for each study: the study country, sample size, inclusion criteria, exclusion criteria, induction and maintenance immunosuppression, HAART regimen, mean CD4 T-cell counts (CD4 counts) pre-transplant and post-transplant, infectious complications, post-transplant neoplasia, PS and GS at 1 and 3 years, and AR rate. In order to analyse data of Infectious complications (IC), all infections requiring hospitalization were registered.

\section{Quality grading of studies}

The quality of each study used for the meta-analysis was assessed based on the Newcastle-Ottawa-Scale (NOS) for cohort studies [6]. The evaluation of study quality included the following three categories: (i) selection (4 items), (ii) comparability (2 items), and (iii) the assessment of outcome (3 items). The NOS ranges from zero to a maximum of 9 points. Five authors $(X \mathrm{Z}, \mathrm{W} X, \mathrm{~S}$ $\mathrm{Z}, \mathrm{Y} \mathrm{X}$ and $\mathrm{Y} \mathrm{Z}$ ) independently assessed the articles. The overall NOS score was determined as the median of all 5 individual NOS assessments. Study quality was graded as good ( $\geq 8$ points), fair ( 6 or 7 points), and poor ( $\leq 5$ points) [6].

\section{Data analysis}

We undertook the descriptive analyses to identify the number of studies with relevant data, the countries where the studies were conducted, and other population attributes. The transplant outcome data were pooled using different transformations according to their different normal distribution conditions.

The data for PS, GS, AR, IC at 1 year and PS at 3 years were analysed using log transformation.

The data for GS at 3 years were analysed using arcsine transformation.

The transformed data were combined to estimate the pooled percentages with $95 \%$ confidence intervals using a random-effects model.

The transformed data were combined to estimate the pooled percentages with $95 \%$ confidence intervals using a random effects model [7] and presented as forest plots. We assessed the heterogeneity among studies using the Cochran $\mathrm{Q}$ test $\left(\chi_{\mathrm{n}-1}^{2} ; \mathrm{p}<0.05\right.$ to denote statistical significance) and estimated the amount of variation by $\mathrm{I}^{2}$ [8]. Statistical sources of heterogeneity were explored by examining the relationship between one or more study-level characteristics and the effect sizes that were observed in the studies using weighted least squares meta-regression. A rank correlation test of funnel plot asymmetry ( $\mathrm{z}$ ) was used to assess the presence of publication bias. Statistical analysis was performed using the $R$ statistical software package (R Development Core Team, Vienna, Austria; URL: http://www.R-project.org; version 2.9.0), using the software libraries 'meta' and 'metafor', for the meta-analysis and meta-regression models, respectively.

\section{Results}

\section{Systematic study review}

The search strategy identified 86 citations (Fig. 1), and among these, we identified 53 studies that appeared to bge relevant to our study. Finally, 27 of these studies, containing 1670 cases, met the inclusion criteria. Agreement between reviewers for assessment of study eligibility was $100 \%$. 

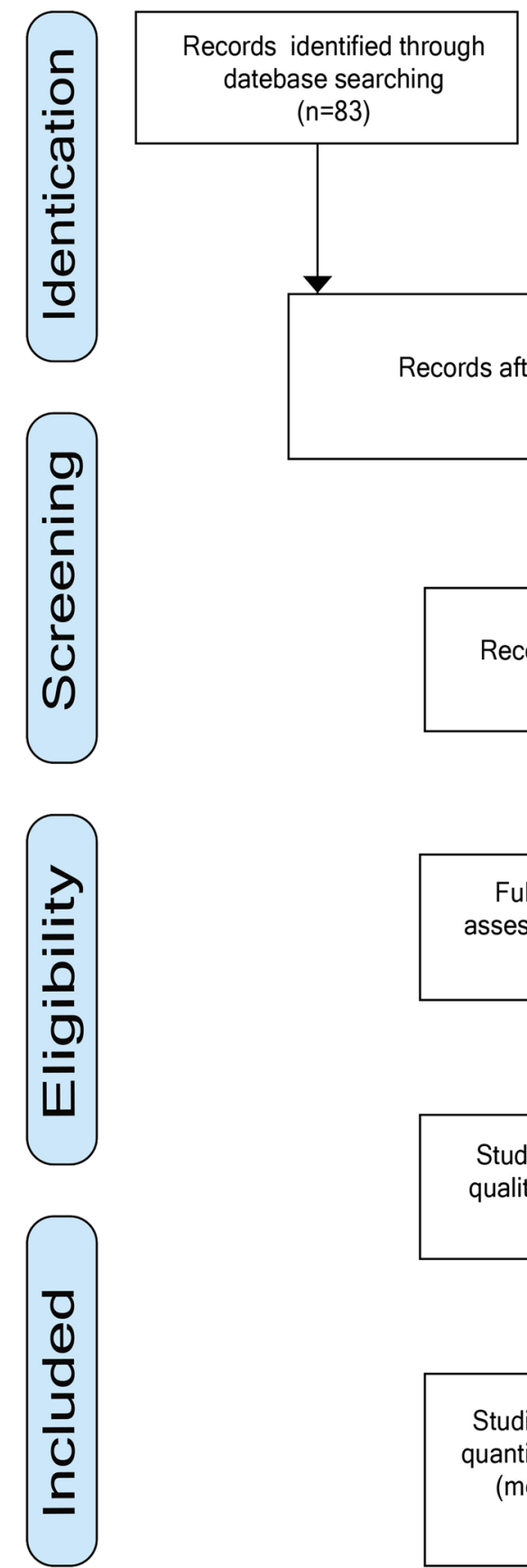

Fig. 1 PRISMA flow chart of literature research

Detailed characteristics of all included studies are provided in Table 1. A majority of the studies were conducted in the US or Europe. All these details are summarized in Tables 2 and 3.

Regarding immunosuppression and rejection, most of the patients received antibody induction therapy with different regimens containing basiliximab, daclizumab, antithymocyte globulin (ATG) or methylprednisolone. The maintenance regimens were mainly composed of cyclosporin A (CSA), mycophenolate mofetil (MMF), tacrolimus (TAC) and steroids, which were the same as the maintenance regimens for HIV-negative patients.

Mean CD4 counts were steady in most of the patients. As we observed, in all the cohorts with available data 


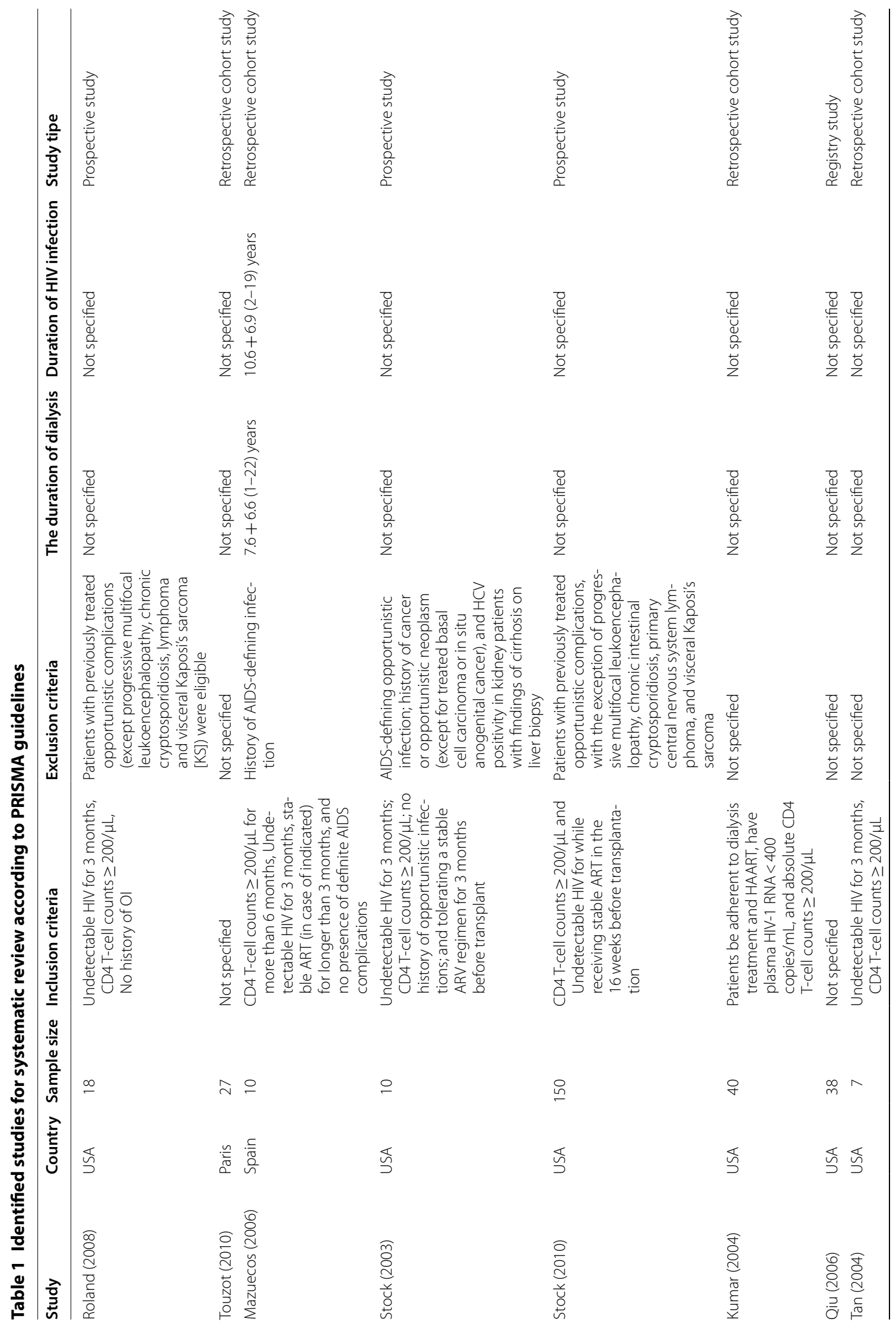




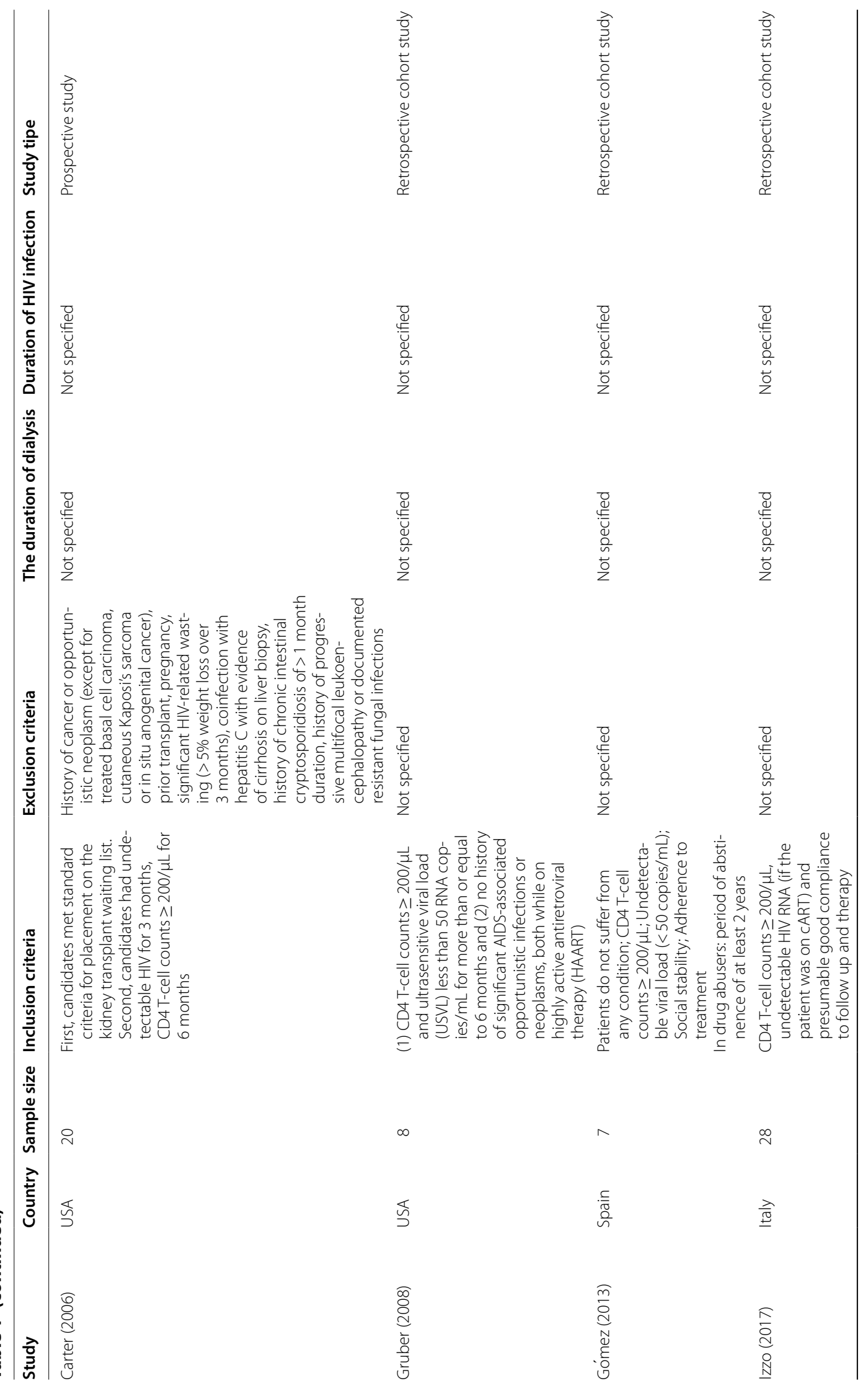




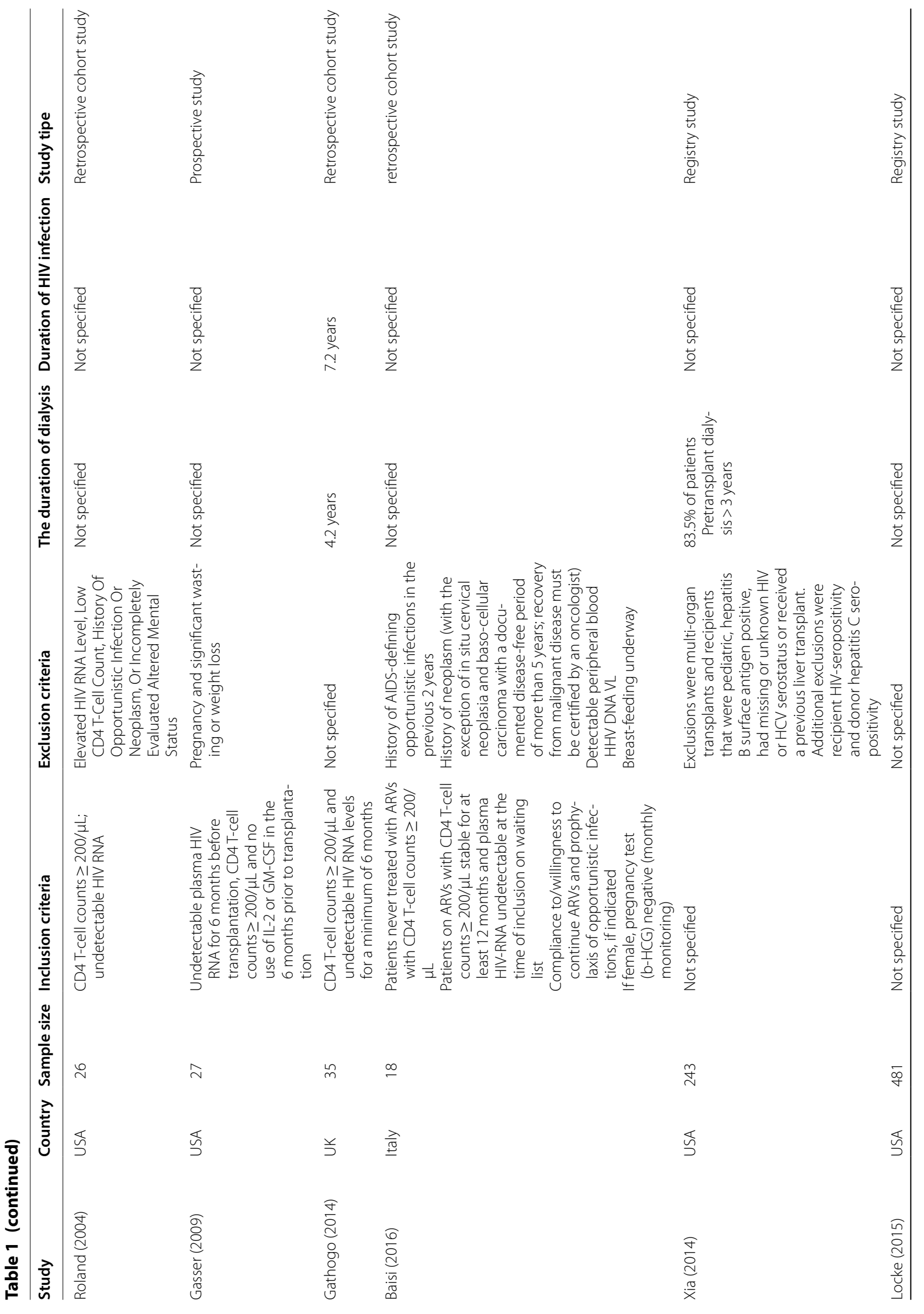



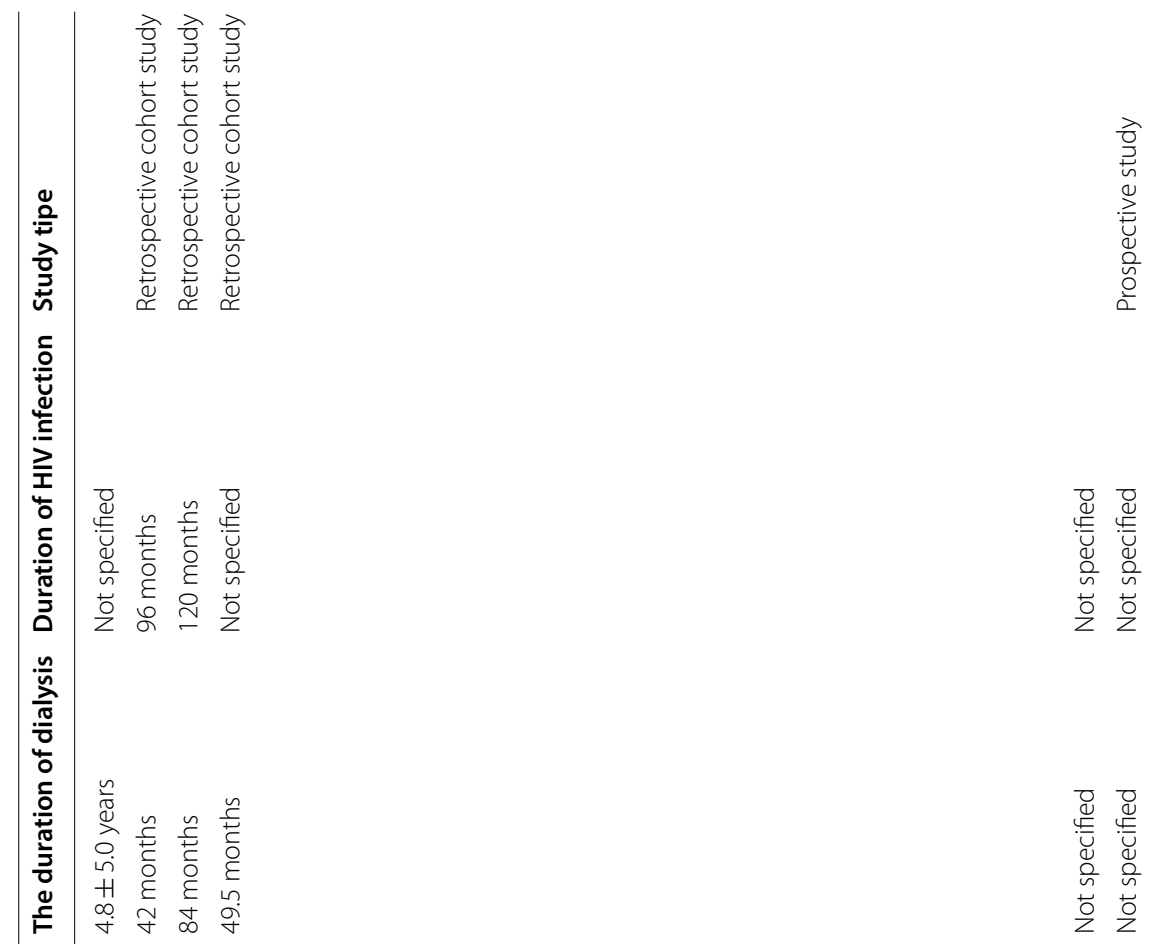

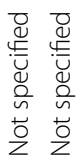

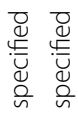

한
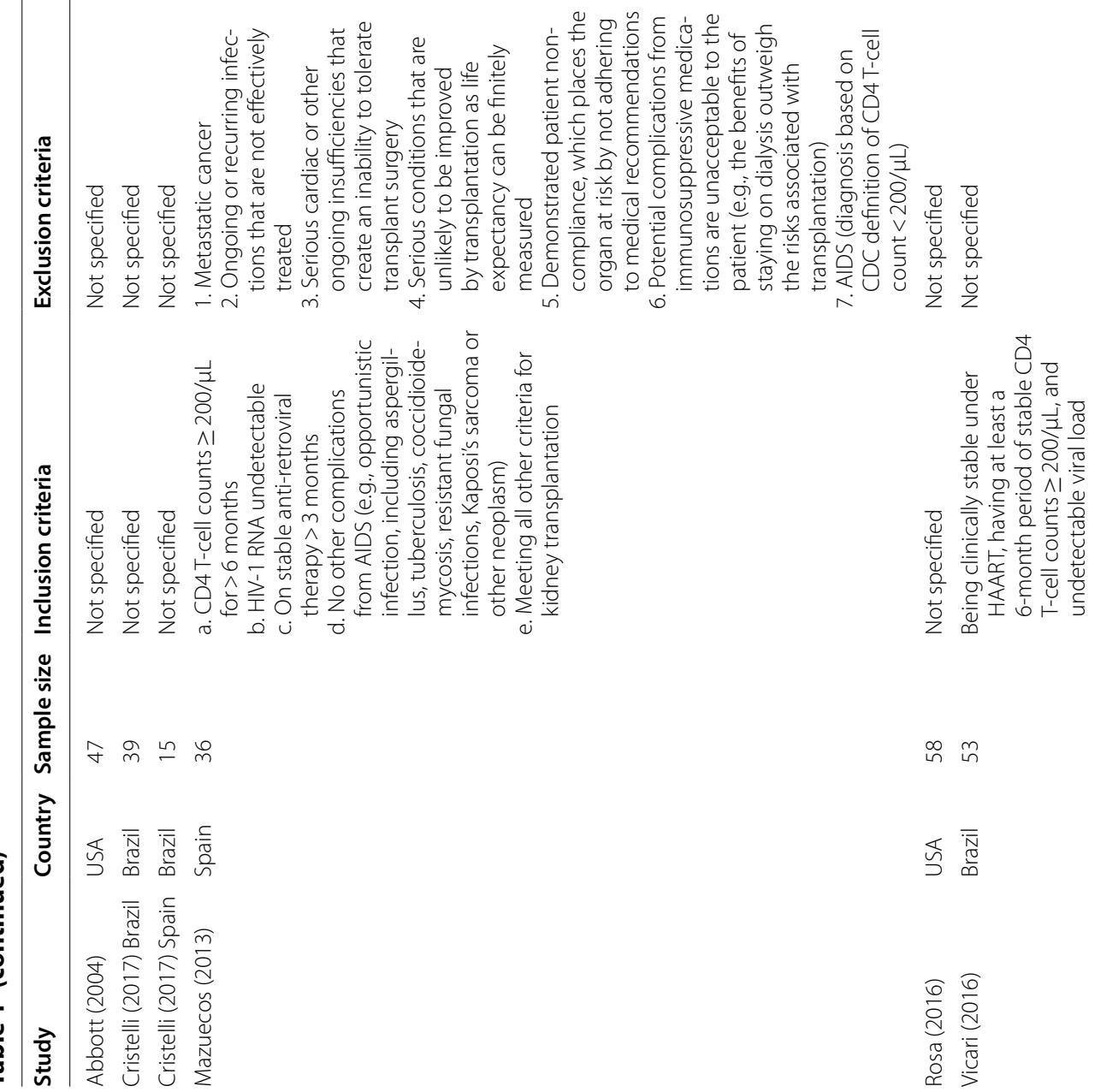

$\stackrel{\infty}{n} n$

范离

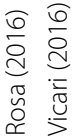




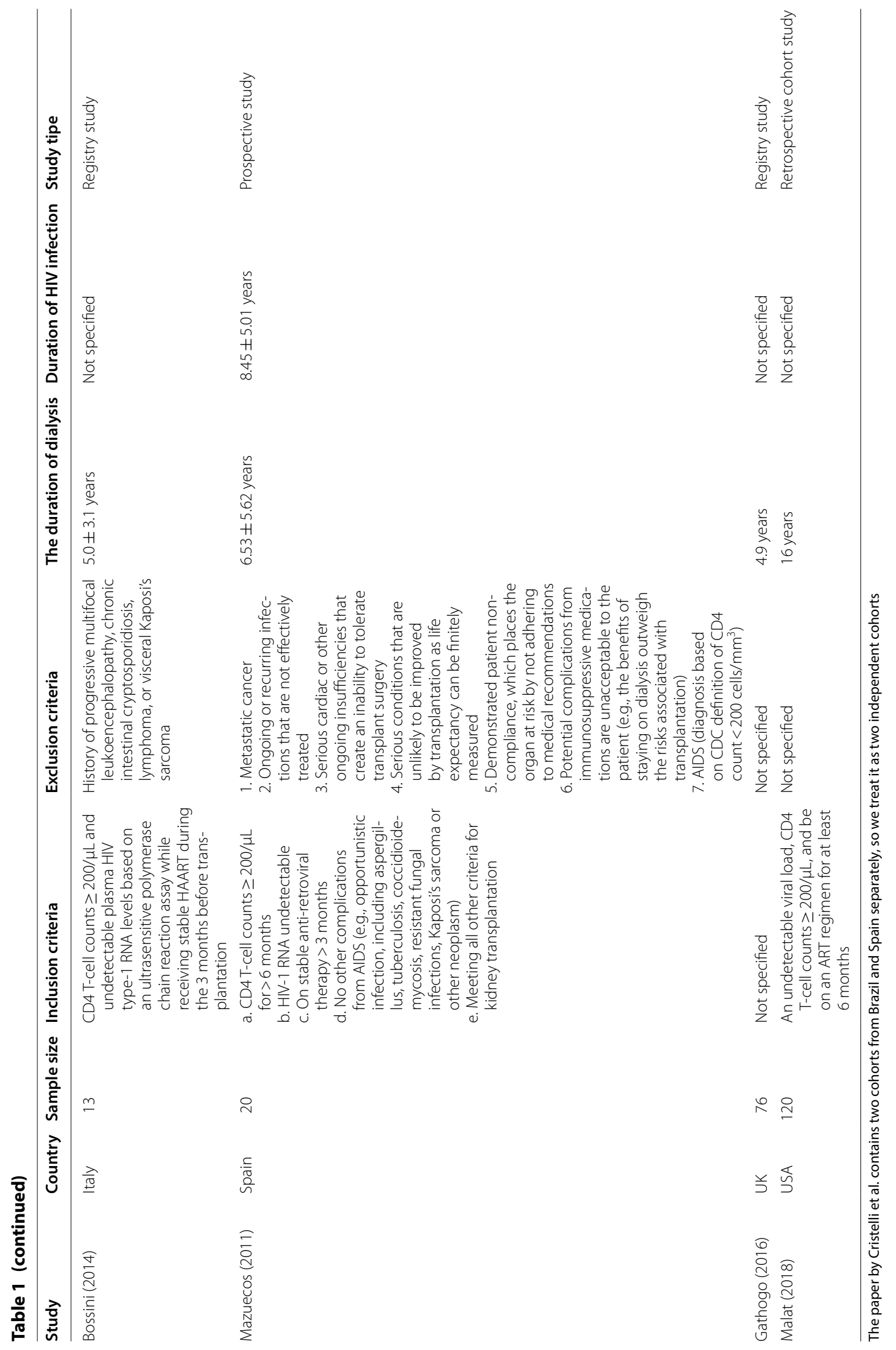




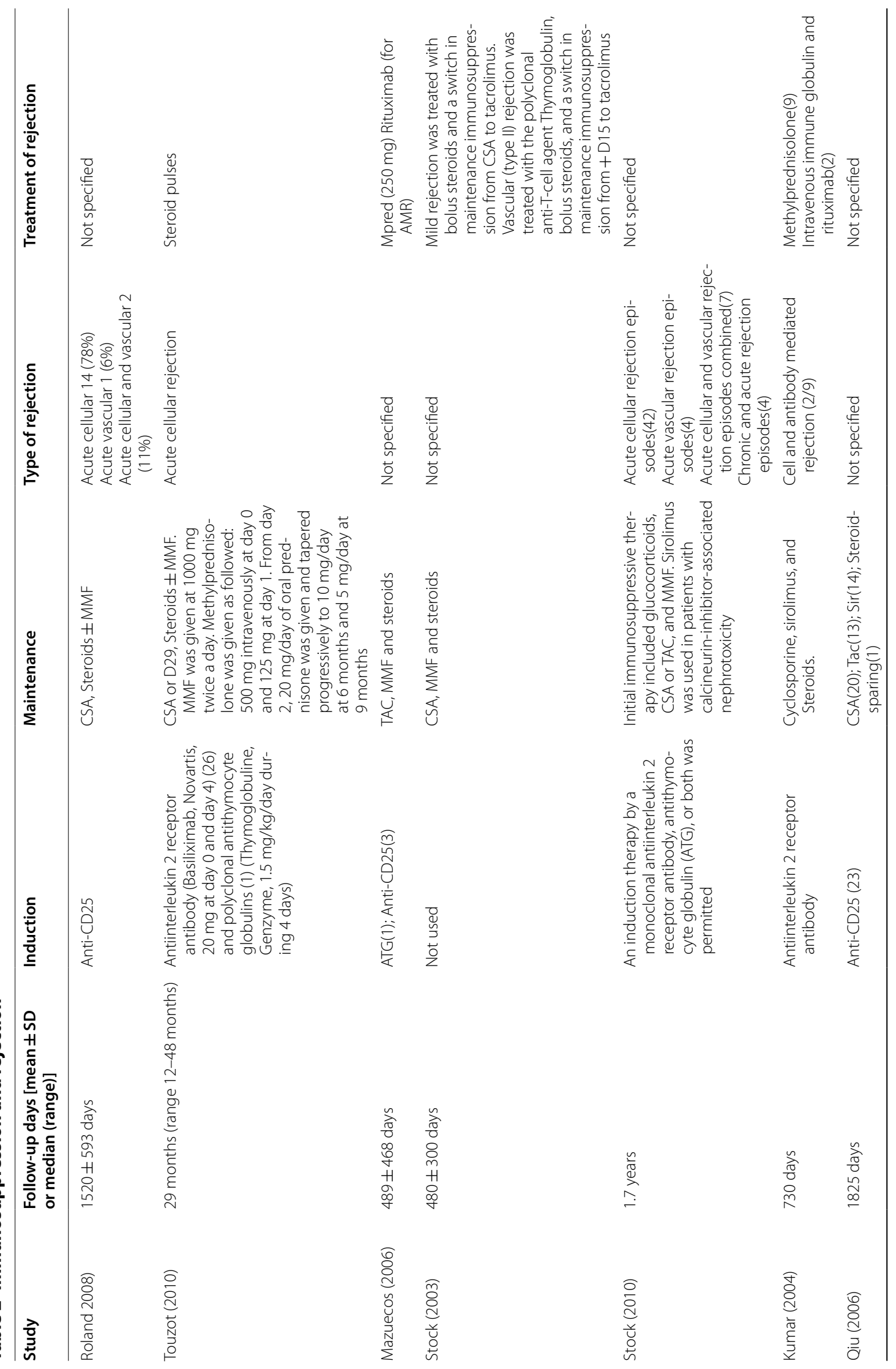




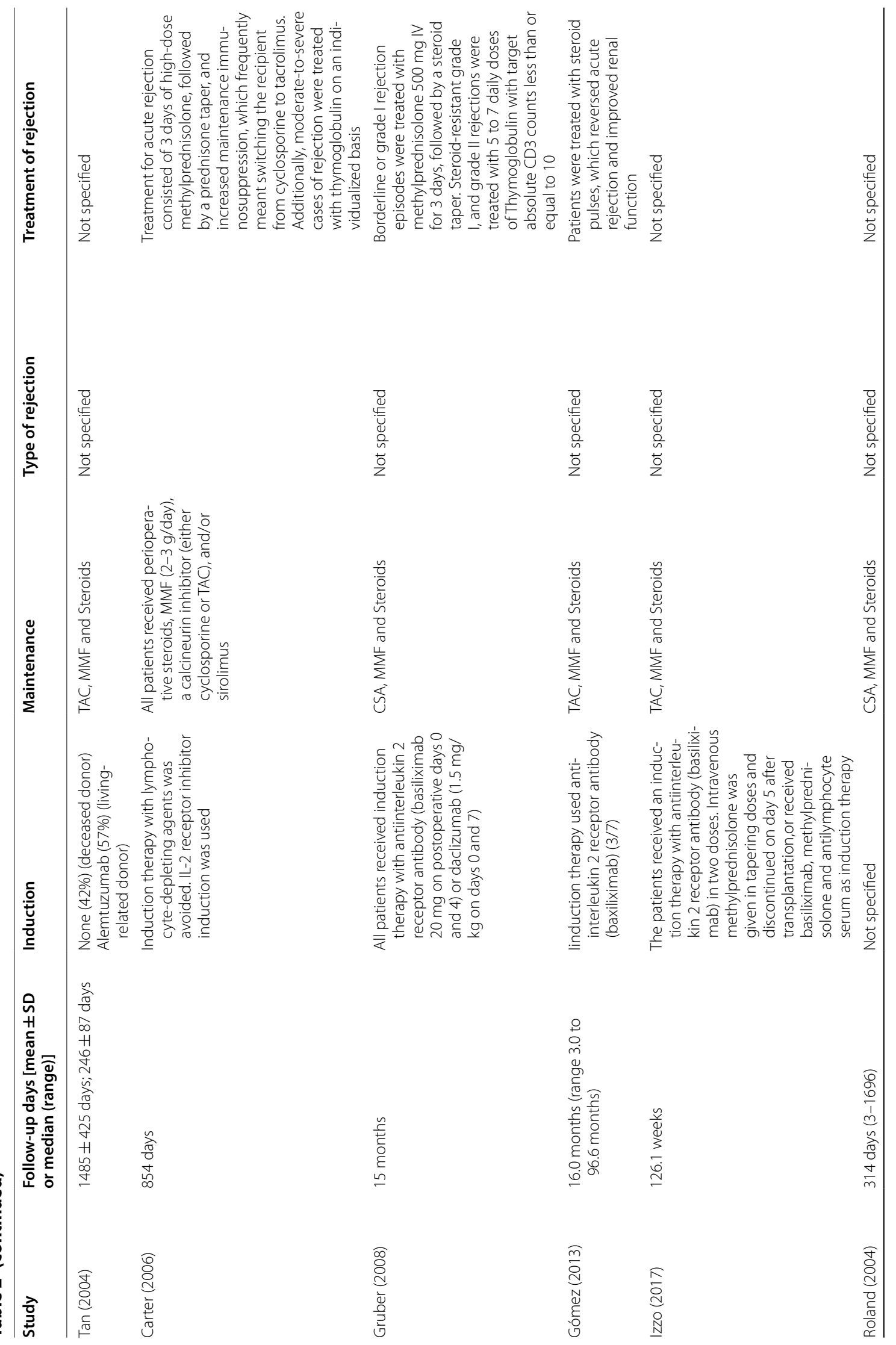




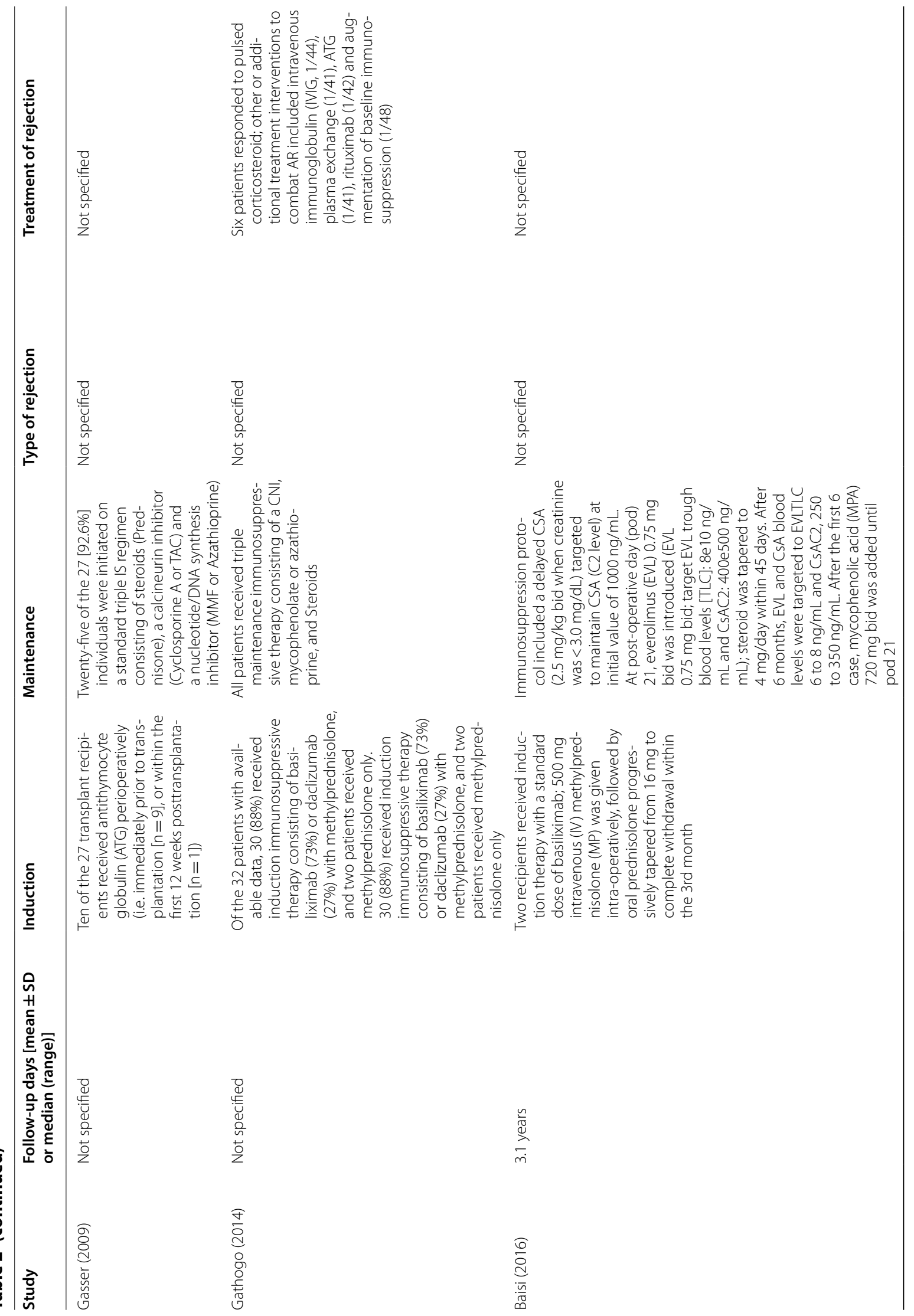




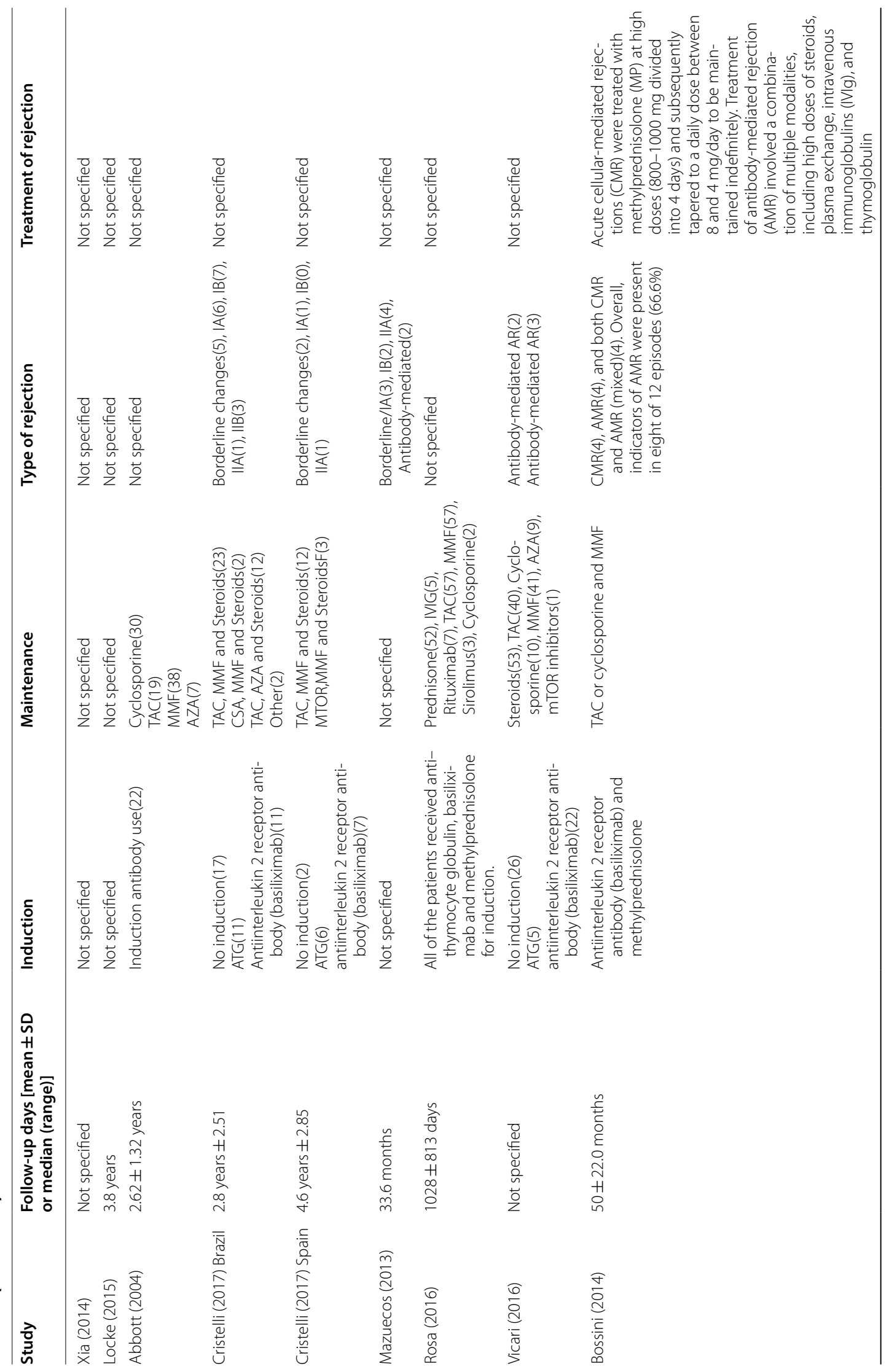




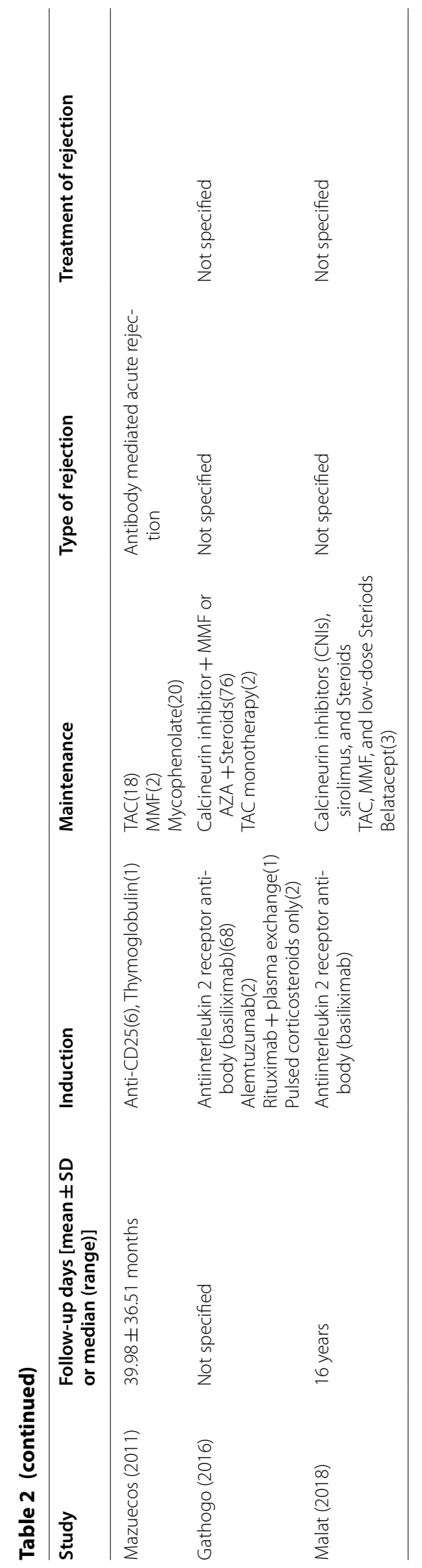




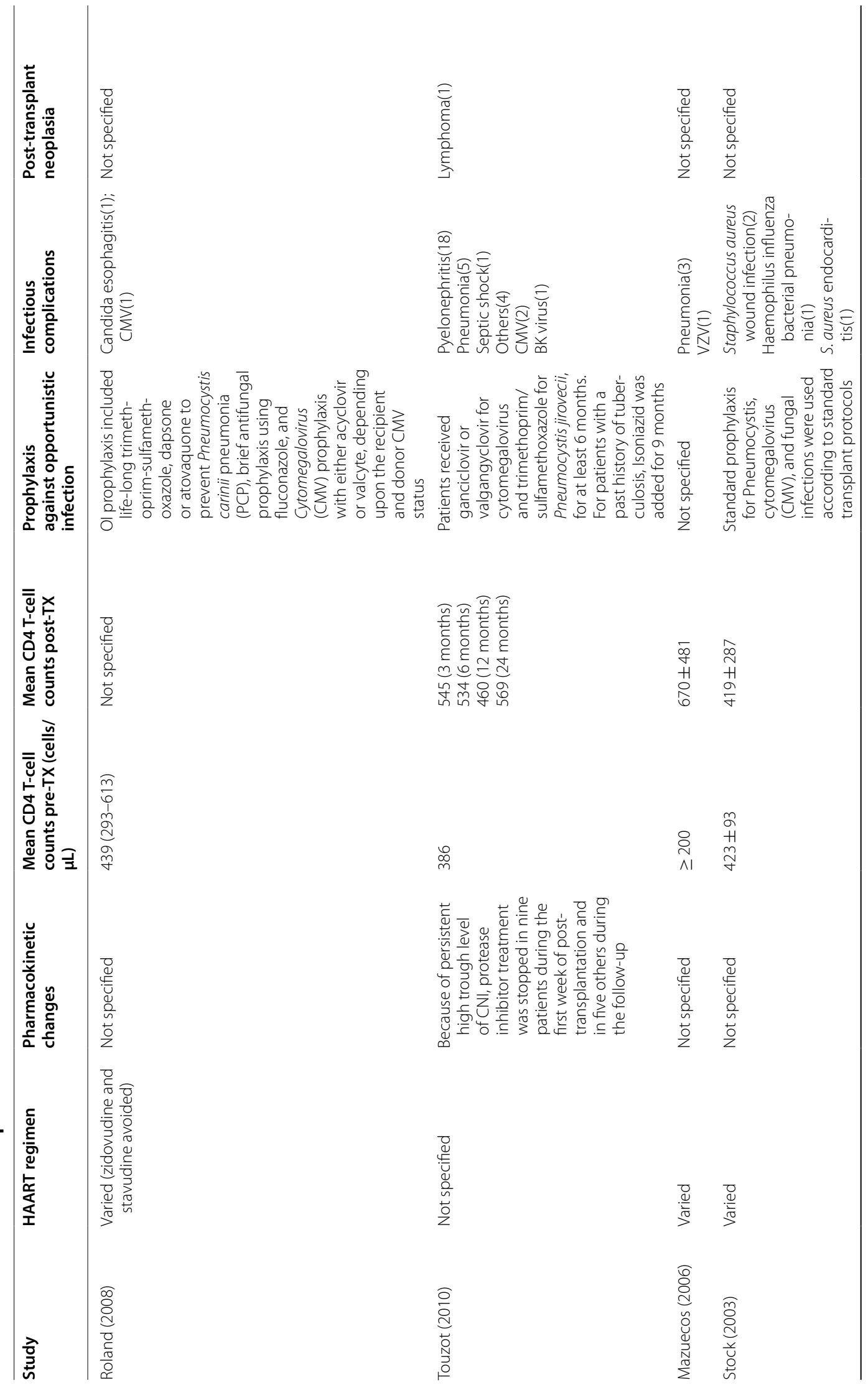




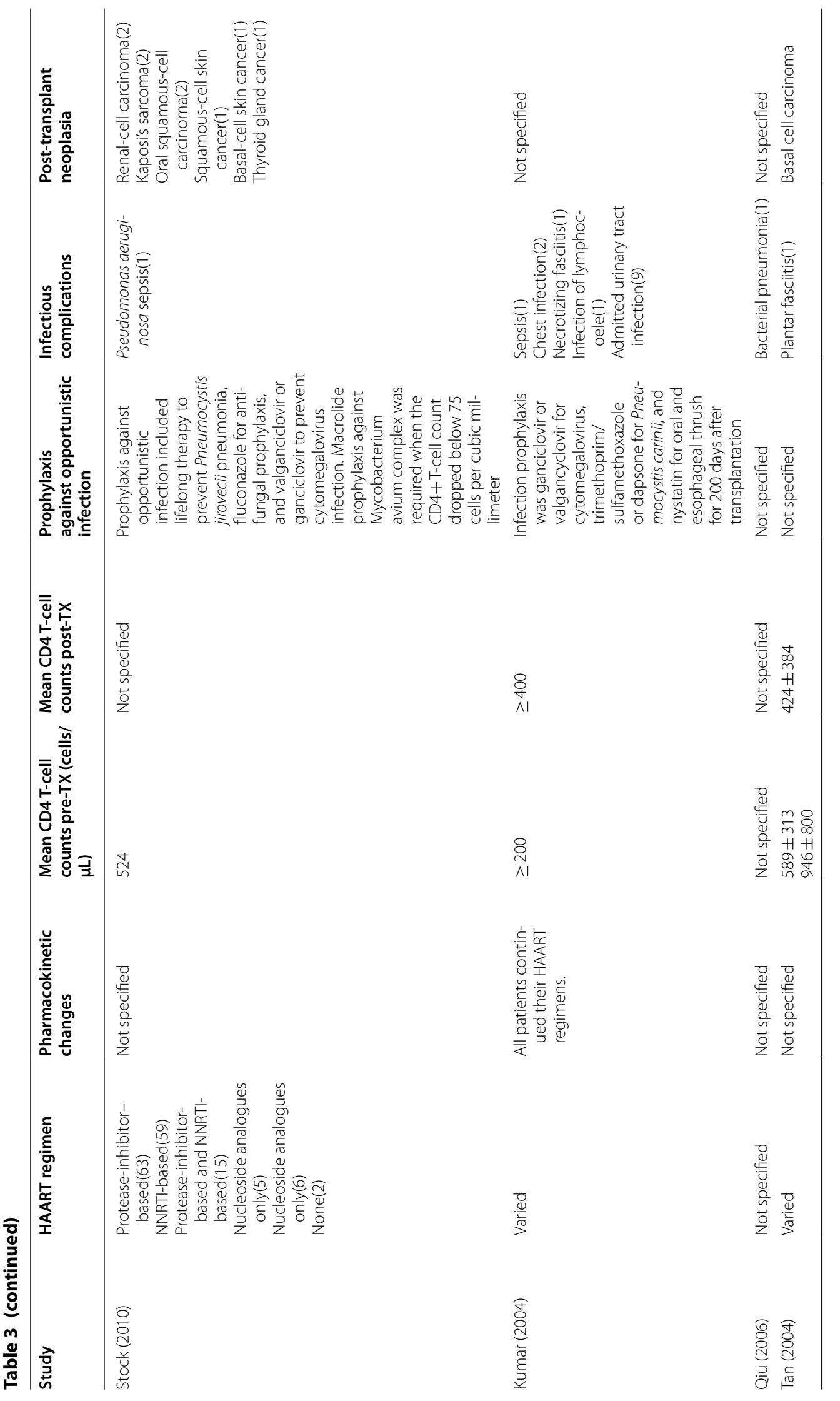




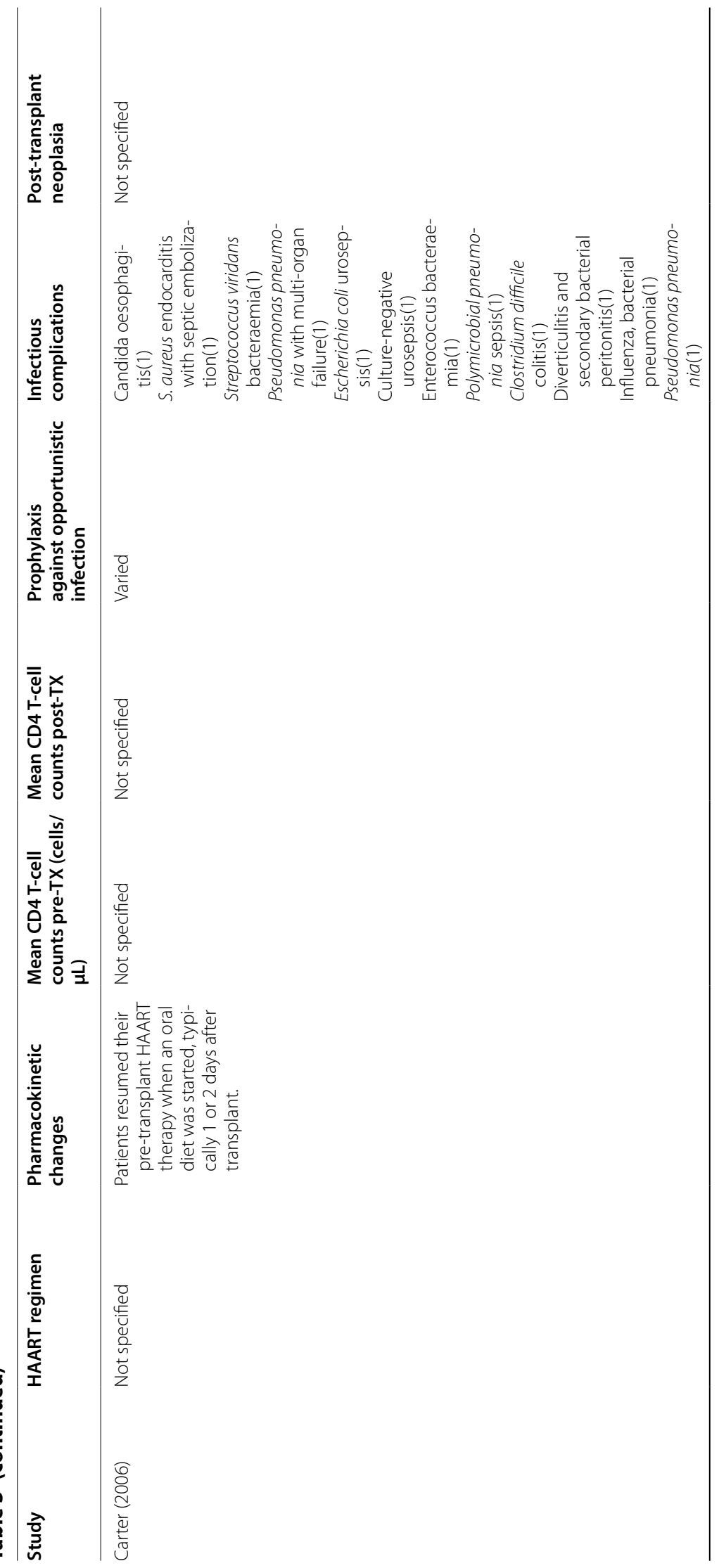




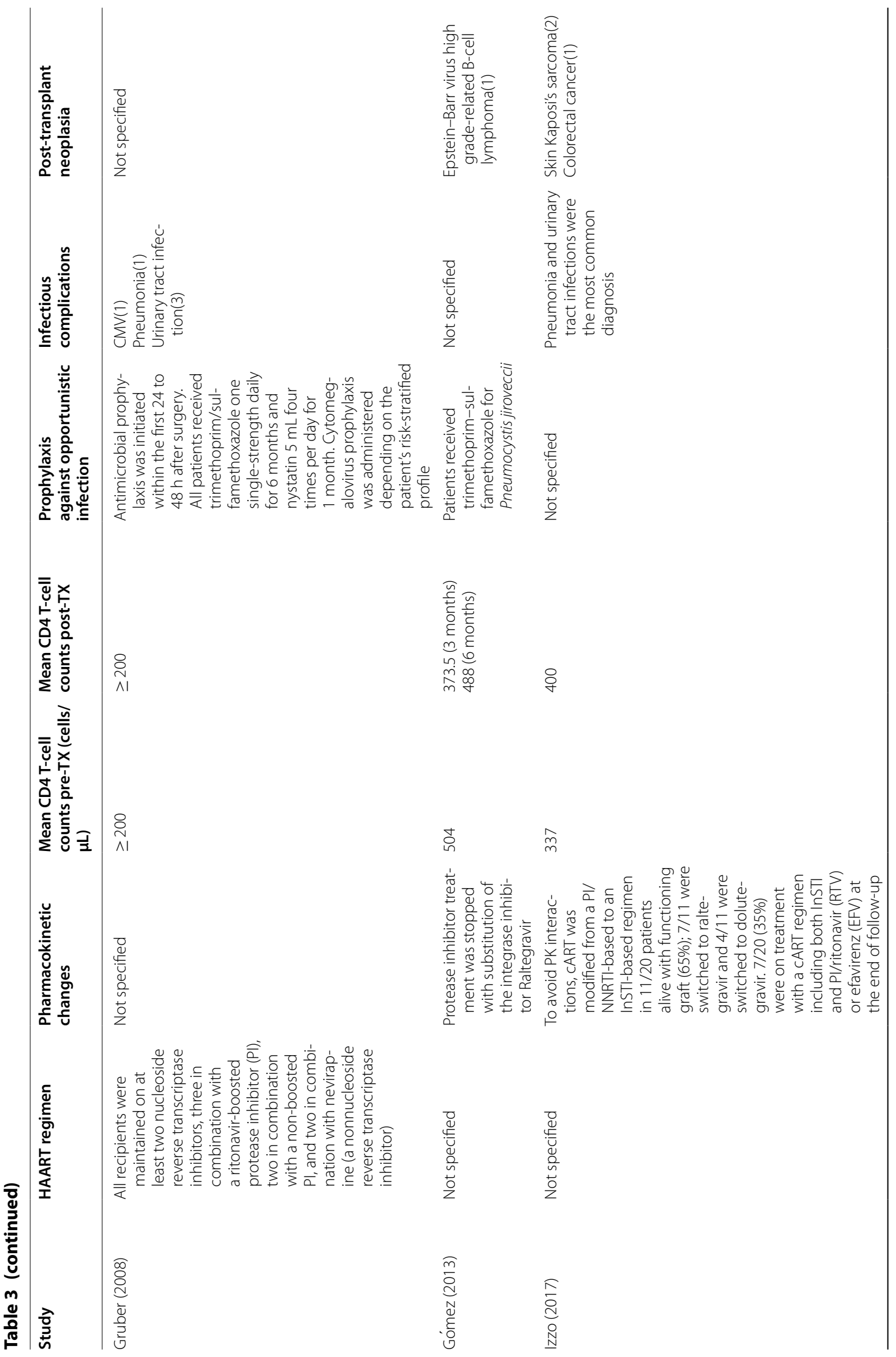




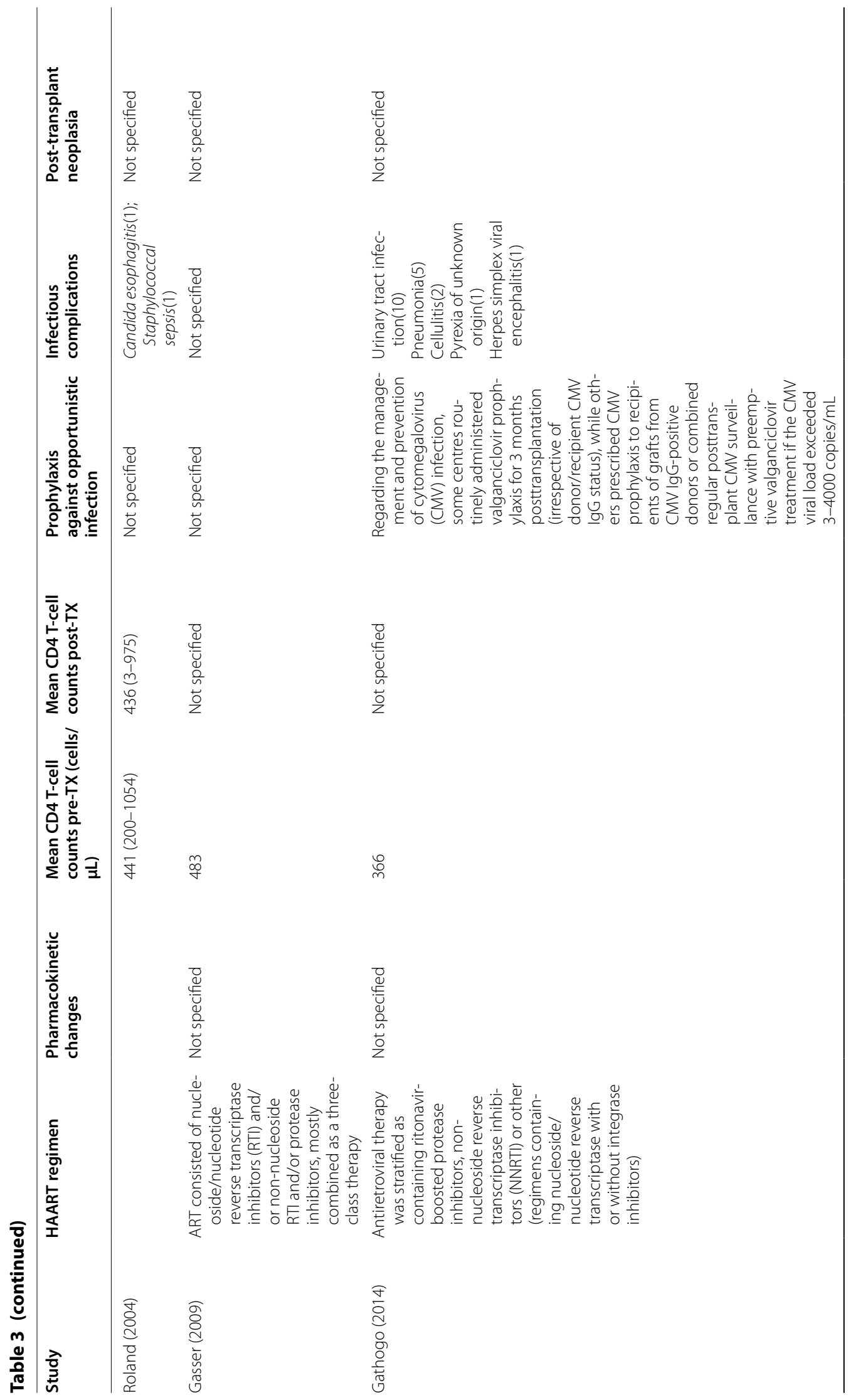




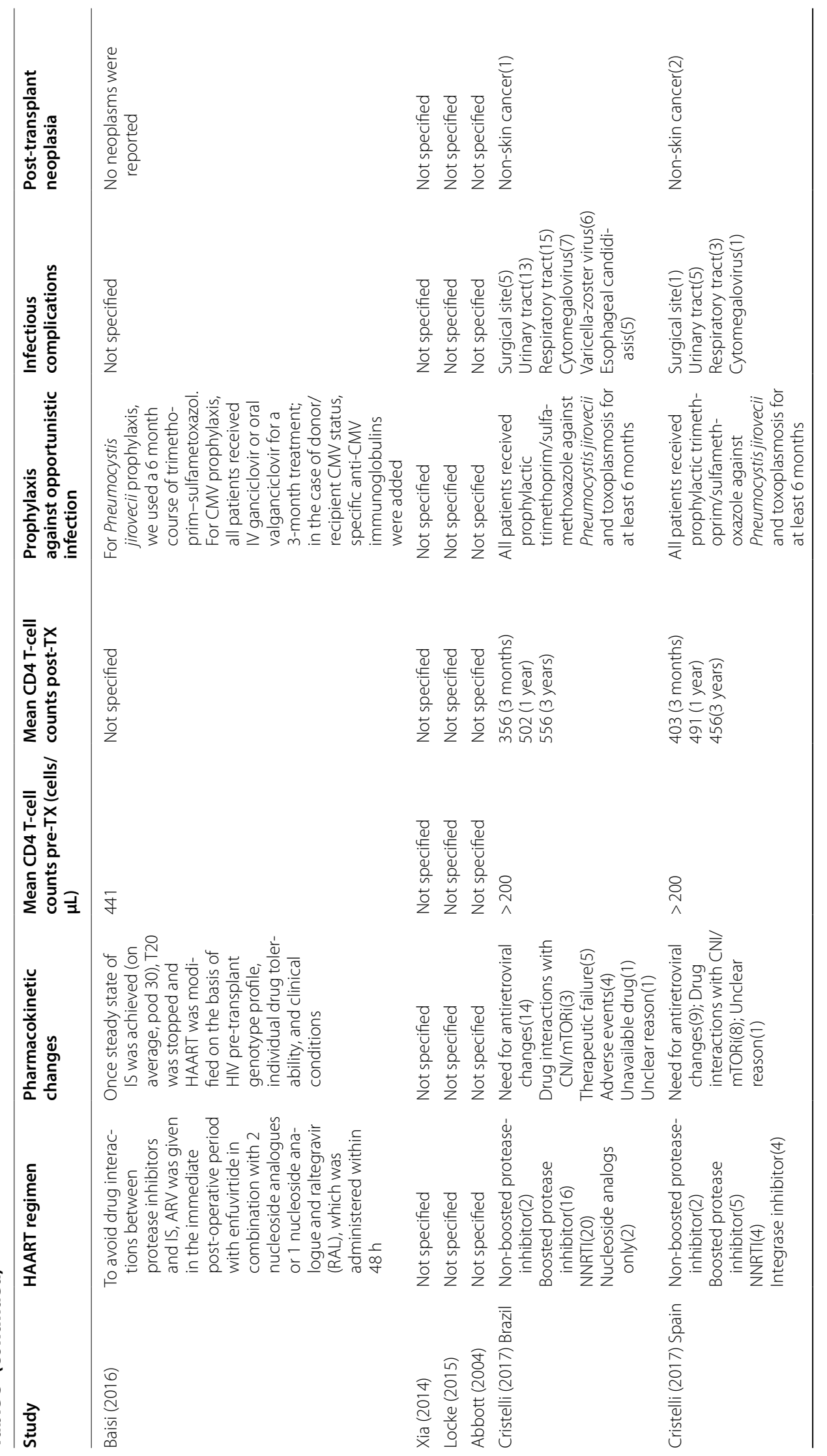




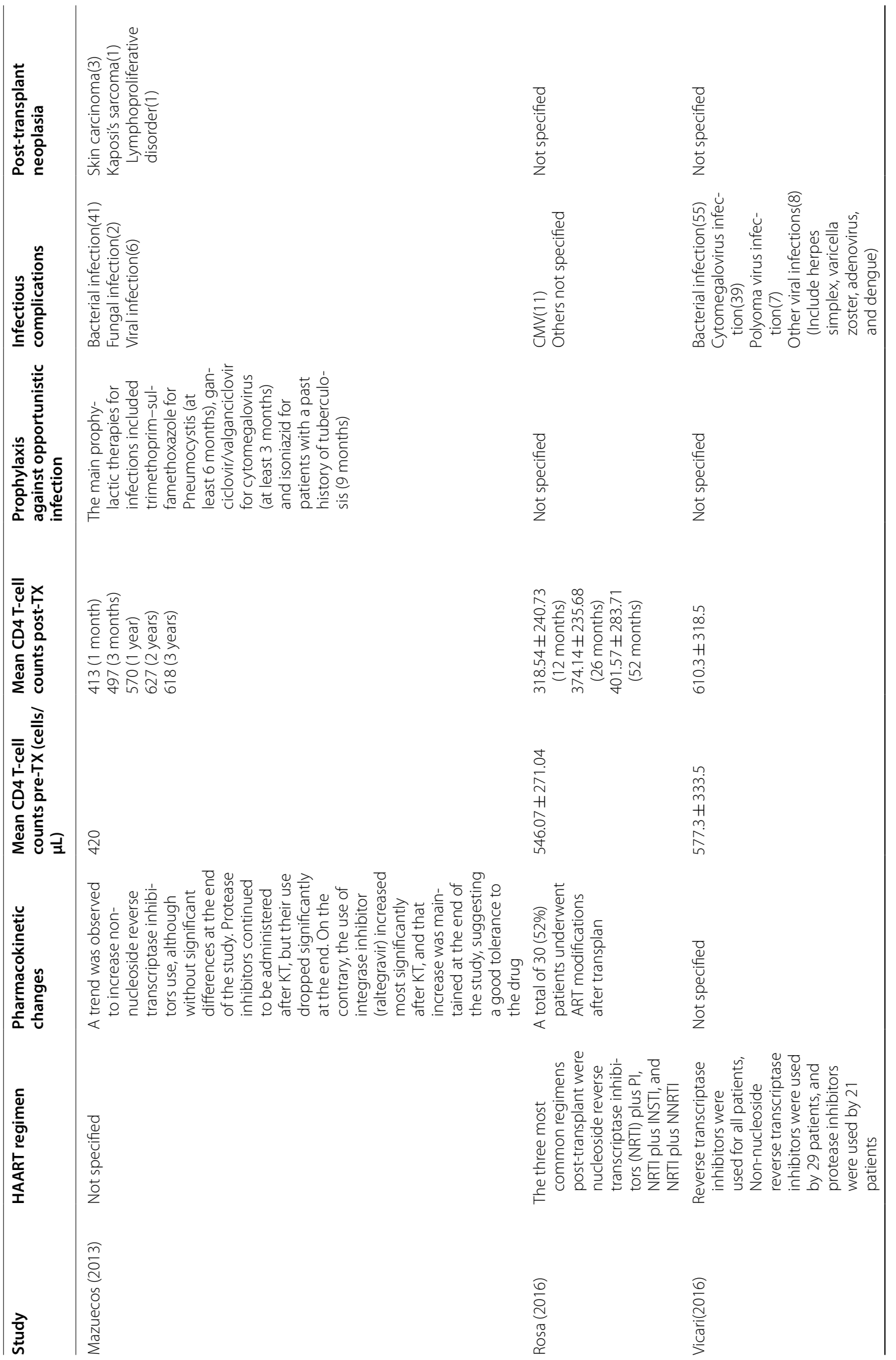




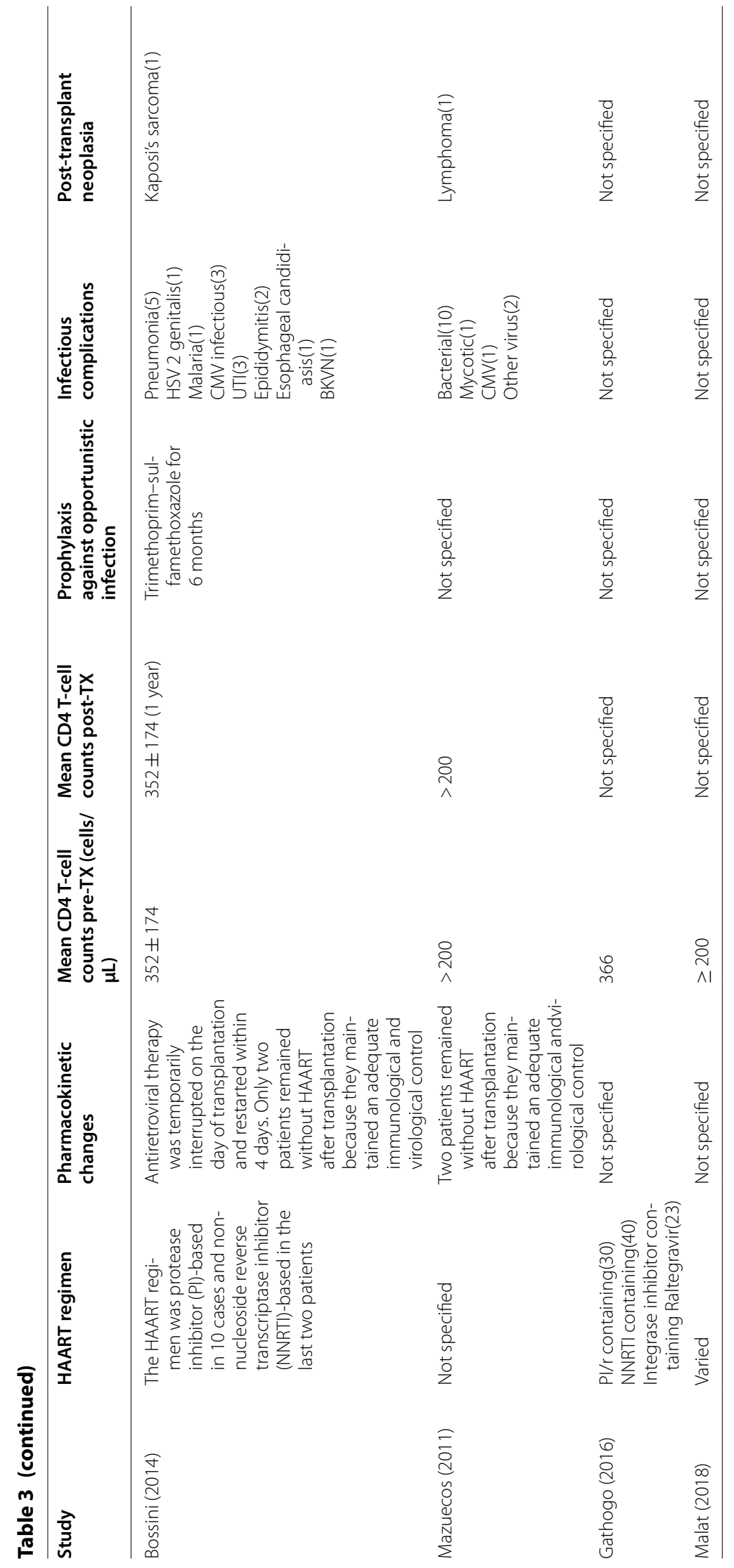


(22/27 cohorts), mean CD4 counts pre-TX and post-TX were greater than 200 cells $/ \mu \mathrm{L}$, and even elevated post transplantation.

Prophylaxis against opportunistic infection was common in most studies as follows: patients received ganciclovir or valganciclovir for cytomegalovirus and trimethoprim/sulfamethoxazole, dapsone or atovaquone for Pneumocystis jirovecii for at least 6 months.

Kaposi's sarcoma and skin cancer were the most observed post-transplant neoplasia. As we showed in Table 3, in all the cohorts with available data (11/27 cohorts, 360 cases in total), there are 6 cases of Kaposi's sarcoma, 6 cases of skin cancer, 4 cases of lymphoma and 9 cases of other neoplasia.

\section{Quality of studies included in the meta-analysis}

Each of the 27 studies included in the meta-analysis was assessed by the NOS to investigate the risk of bias within the studies. Table 4 shows the results of the quality assessment. None of the studies had less than three points in the category selection. Two studies controlled for age and gender, and 9 controlled for other factors, such as the HAART regimen and/or immunosuppression therapy. Finally, 5 studies were graded as good quality and 22 as fair quality.

\section{Patient survival post KT}

Twenty-seven studies reporting PS at 1-year post KT included PS estimate to post KT for 1429 patients; however, only nine studies including 509 patients reported PS at 3 years. The results of the analysis are shown in Figs. 2 and 3. At 1 year, $97 \%\left(95 \%\right.$ CI $\left.0.95 ; 0.98, \mathrm{I}^{2}=36 \%\right)$ of patients survived, while $94 \%$ (95\% CI 0.90; 0.97, $\mathrm{I}^{2}=44 \%$ ) of patients survived at 3 years.

\section{Graft survival post KT}

Twenty-six studies including 1391 patients reported GS at 1 -year post $\mathrm{KT}$, and nine studies including 509 patients reported GS at 3 years. The results of the analysis are shown in Figs. 4 and 5. At 1 year, 91\% (95\% CI 0.88; 0.94, $\left.\mathrm{I}^{2}=69 \%\right)$ of grafts had survived, and GS subsequently declined to $0.81\left(95 \%\right.$ CI $\left.0.74 ; 0.87, \mathrm{I}^{2}=69 \%\right)$ at 3 years.

\section{Acute rejection post $\mathrm{KT}$}

Twenty-five studies including 1051 patients reported $\mathrm{AR}$ post $\mathrm{KT}$ at 1 year, and the results of the analysis are shown in Fig. 6. At 1 year, 33\% (95\% CI 0.28; 0.38, $\left.\mathrm{I}^{2}=60 \%\right)$ of patients had AR.

\section{Infectious complications post KT}

Nineteen studies including 584 patients reported IC post KT at 1 year; the results of the analysis are shown in Fig. 7. At 1 year, 41\% (95\% CI 0.34; 0.50, $\left.\mathrm{I}^{2}=59 \%\right)$ of patients had IC.

\section{Discussion}

To our knowledge, this is the first systematic review and meta-analysis of such a large scale to report the outcomes of $\mathrm{KT}$ in HIV+ patients. We review and meta-analysis the outcomes in HIV+ KT patients, and looks at the 1and 3-year GS/PS and AR rate.

The availability of cART has made KT a feasible treatment for selected HIV+ patients with ESRD, with outcomes somewhat inferior to those observed among the overall population of KT recipients [4, 9-11].

\section{Outcomes of KT}

$\mathrm{KT}$ is now a viable treatment for select patients with HIV and ESRD. Moreover, the high incidence of morbidity and mortality resulting from cardiovascular issues in HIV+ patients [12,13], as well as the negative effects of prolonged steroid use on conditions associated with cardiovascular risk, such as diabetes, dyslipidaemia, and hypertension, are well known $[14,15]$.

However, data regarding long-term outcomes and comparisons with appropriately matched HIV - patients are still lacking.

Locke et al. analysed 510 adult KT recipients with HIV matched 1:10 with HIV-controls. They found that HIV - and HIV mono-infected KT recipients had similar GS and PS, whereas HIV/HCV co-infected recipients had worse outcomes [16].

Izzo et al. found that the survival rate of patients was $82.1 \%$ and functioning grafts was $71.4 \%$ [17], and a recent report from the Italian national transplantation registry showed a PS rate of $95 \%$ and a GS rate of $85 \%$ between 2006 and 2014 [18].

Stock et al. [4] reported a survival rate of $94.6 \% 1$ year after transplantation (88.2\% after 3 years) in a multicentric trial (150 patients), and in a published review with a small number of patients, the survival rate was $93 \%$ within the first year of transplantation (254 patients) [19]. What's more, as the high incidence of co-infection with $\mathrm{HCV}$ in HIV+ patients, co-infection is likely a driver of poor outcomes [20].

In our analyses, at 1 year, PS was 0.97 (95\% CI 0.95; 0.98 ), GS was 0.91 (95\% CI $0.88 ; 0.94$ ), and at 3 years, PS was 0.94 (95\% CI 0.90; 0.97), GS was 0.81 (95\% CI 0.74; $0.87)$.

\section{Immunosuppression therapy}

One of the most challenging goals in solid-organ transplantation is to tailor the immunosuppressive regimen for each individual patient to minimize immunosuppression while still preventing AR. Opportunistic infections 


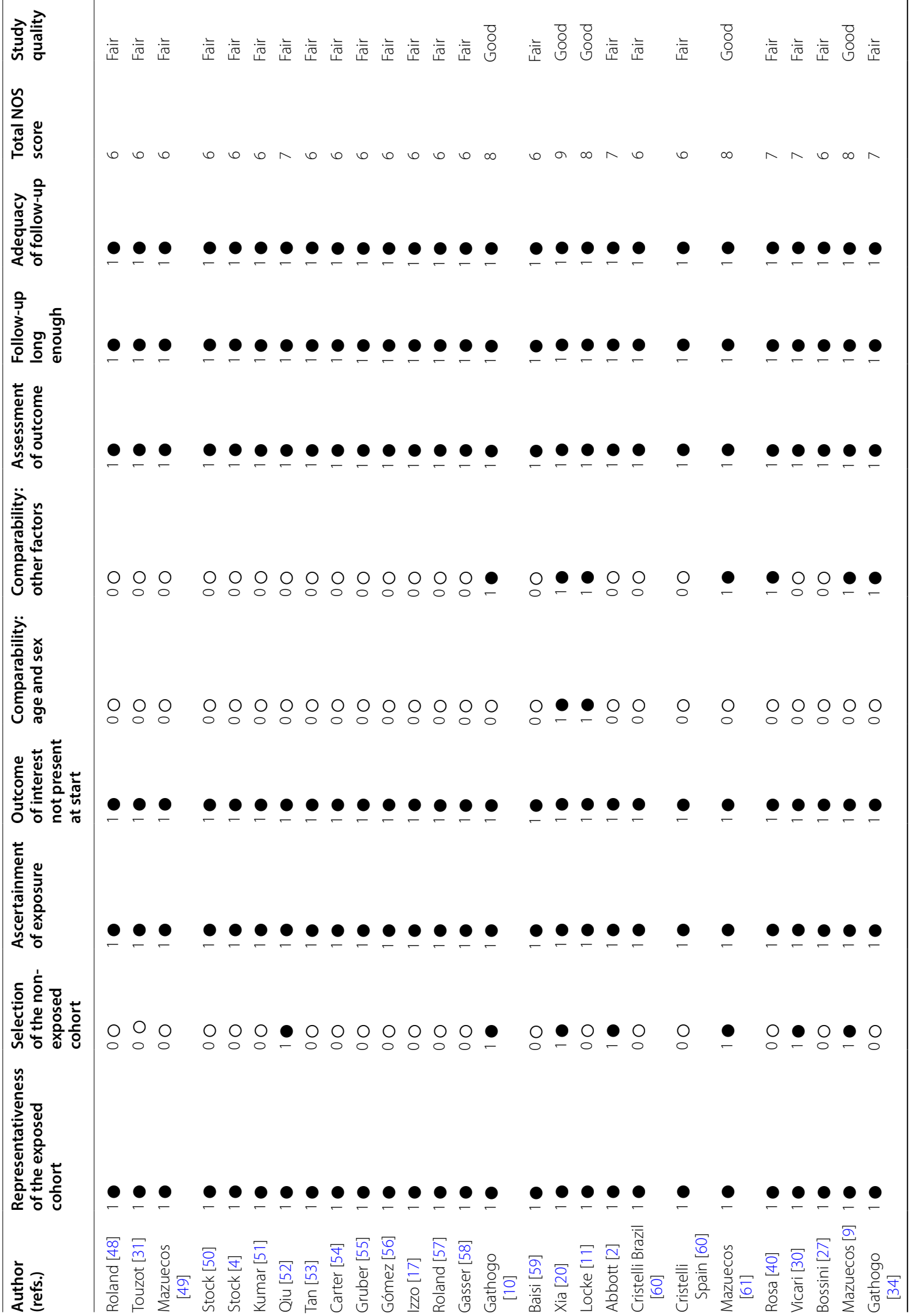




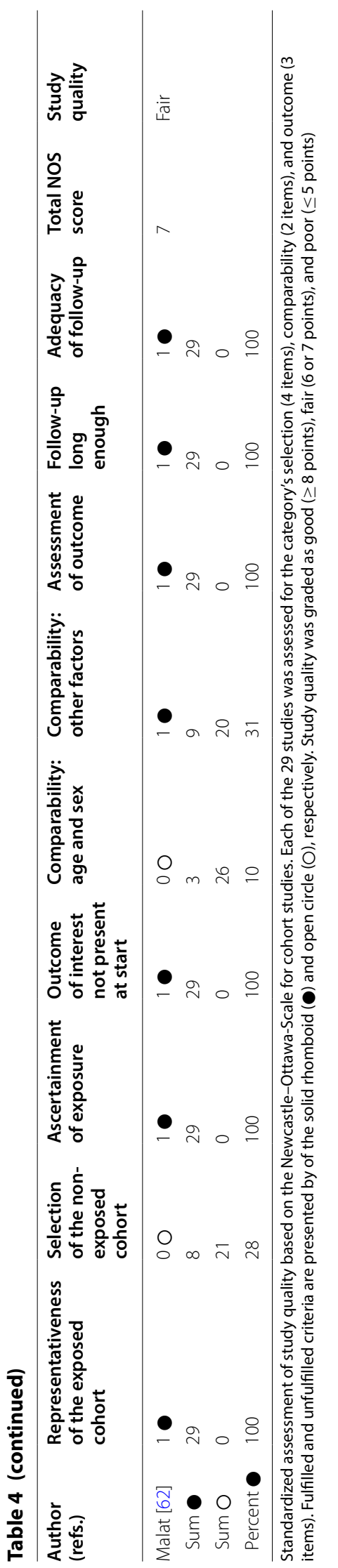




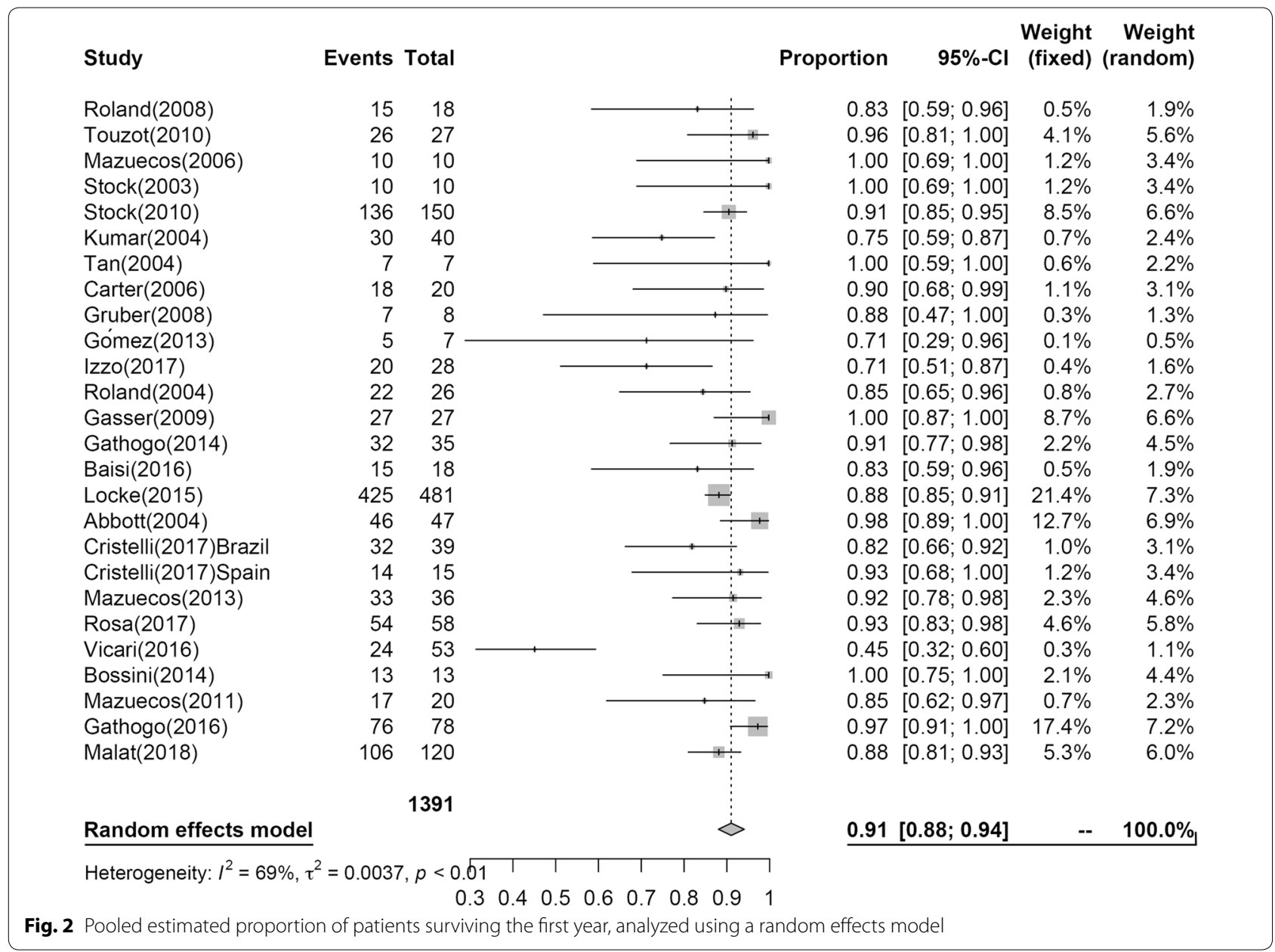

and malignancies often attributed to immunosuppression itself remain a significant cause of death after transplantation. In the field of HIV+ organ transplantation, finding a balanced approach to immunosuppression is even more critical.

Currently, the vast majority of $\mathrm{KT}$ patients receive induction immunosuppression, which has been shown to greatly reduce the risk of rejection and improve PS and GS [21]. As shown in our analyses, most of the HIV+ KT patients received induction therapy. The two most commonly used induction agents are ATG and IL-2 receptor blocker (anti-IL2R) [22].

Guidelines from the Kidney Disease: Improving Global Outcomes transplant working group recommended antiIL2R as the first-line treatment for patients at low risk for rejection and ATG for those at high risk [23].

Despite being the standard of care for most HIV patients, the use of induction immunosuppression for $\mathrm{HIV}+$ patients, particularly ATG, remains controversial.
On the one hand, HIV + patients have high rates of rejection and thus stand to benefit significantly from induction. On the other hand, the risks posed from prolonged lymphocyte depletion are of major concern given that HIV+ patients are perceived to already threaten $\mathrm{T}$ cell populations and reduced immunity, both states that are associated with an increased risk of opportunistic infections.

A recent study showed that ATG induction was associated with long-term impairment of $\mathrm{T}$ cell function and related infections, even after the patients had normalized CD4 counts [24]. This finding is also a reminder that the CD4 counts incompletely assesses the recovery of an immunocompetent CD4 T cell pool.

The incidence and severity of IC following transplantation are largely dictated by the recipient's capacity for immune reconstitution. A study by Suarez et al. indicate that ATG-induced CD4 lymphopenia can be prolonged, and even at 1 year post transplant, a substantial proportion of patients has CD4 counts $<200 / \mu \mathrm{L}$ [25]. The baseline CD4 counts did not influence the risk of death, graft loss or AR. 


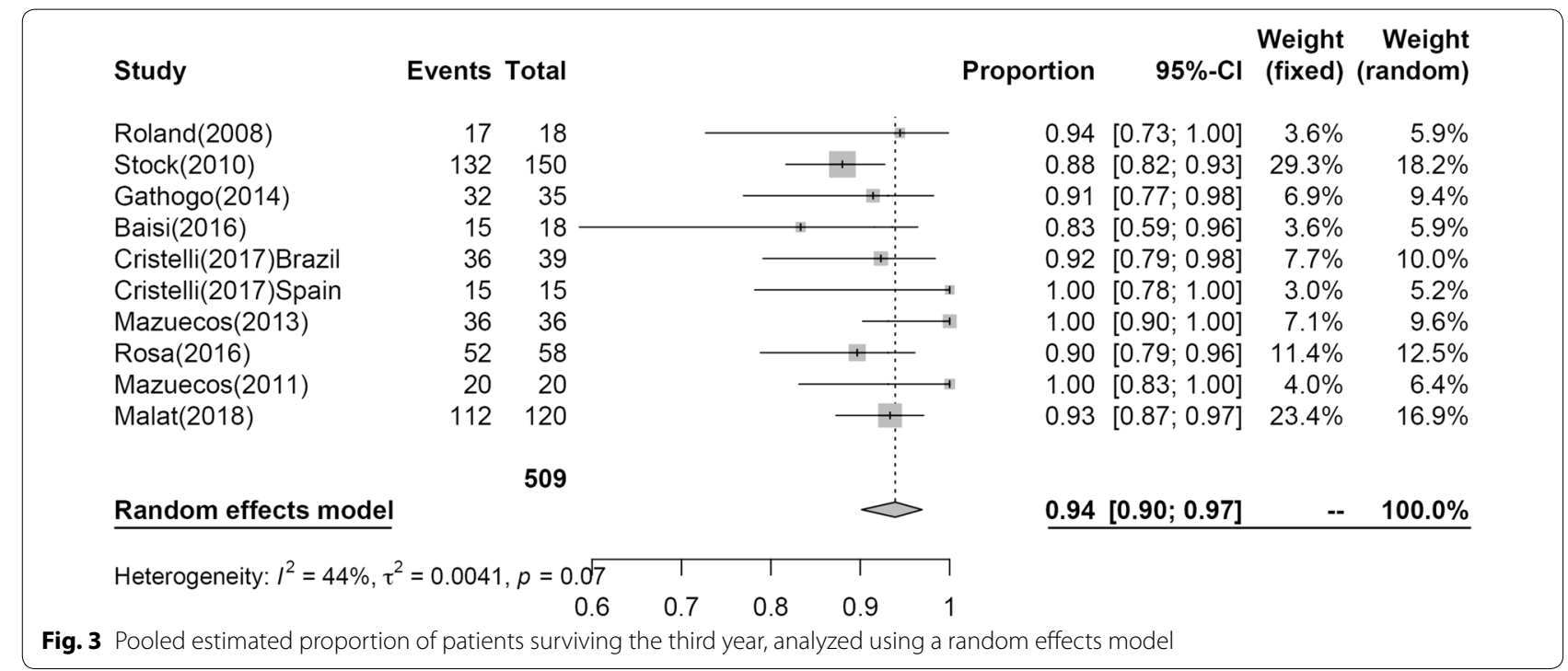

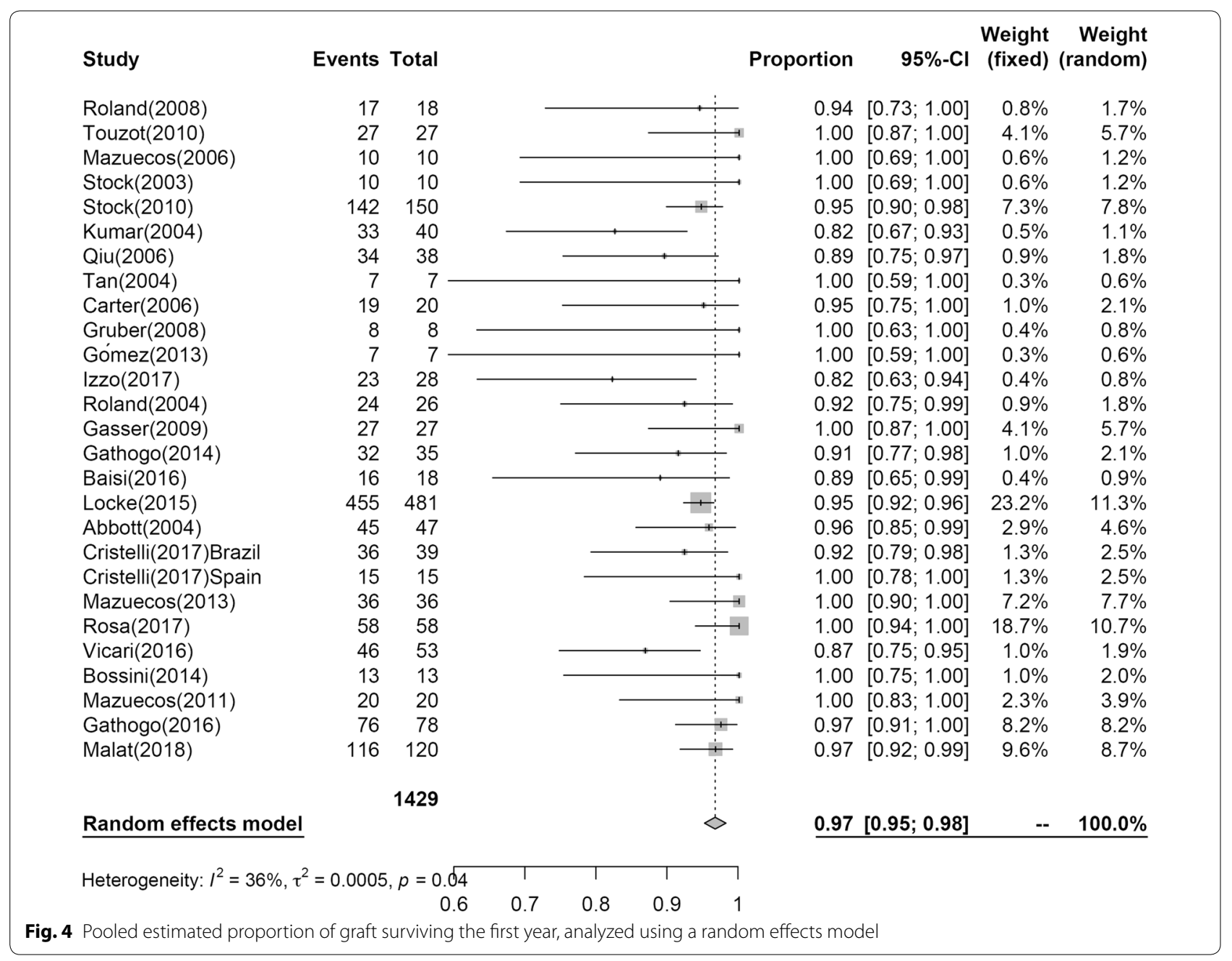




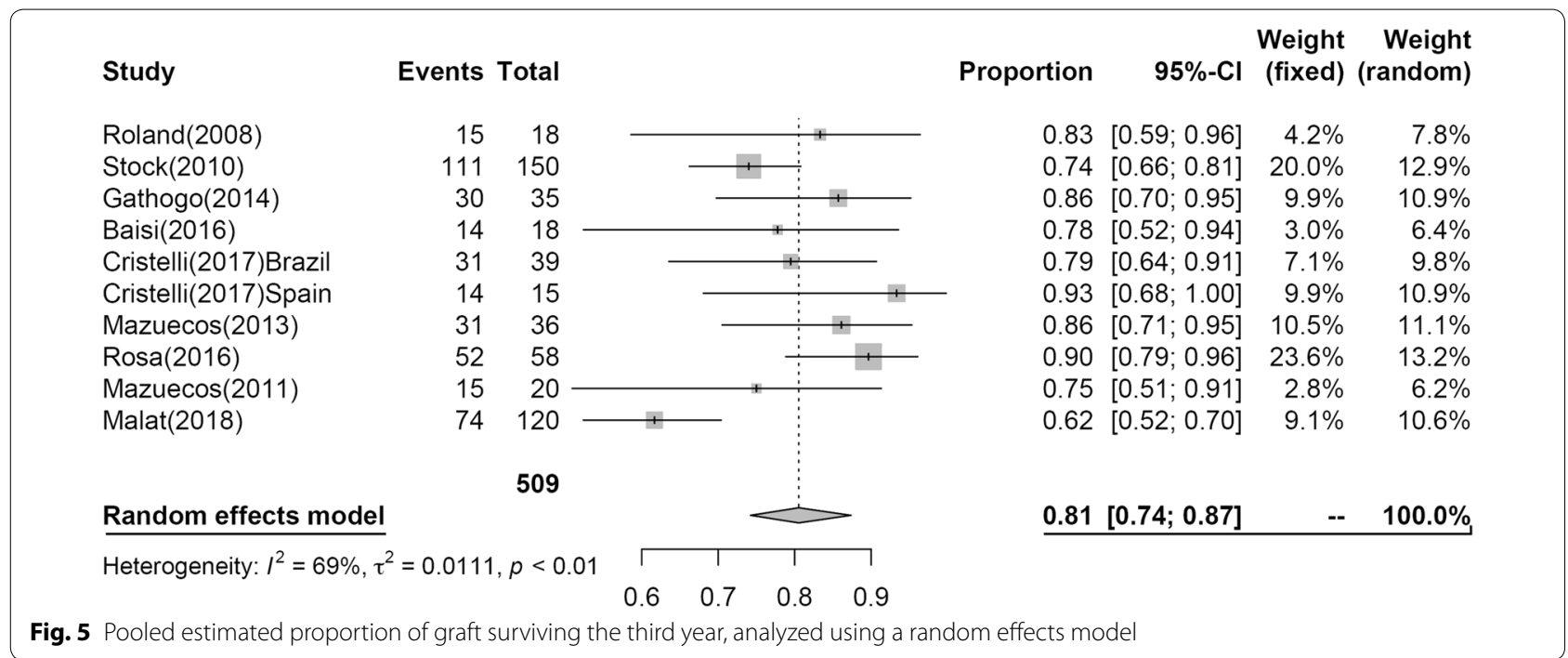

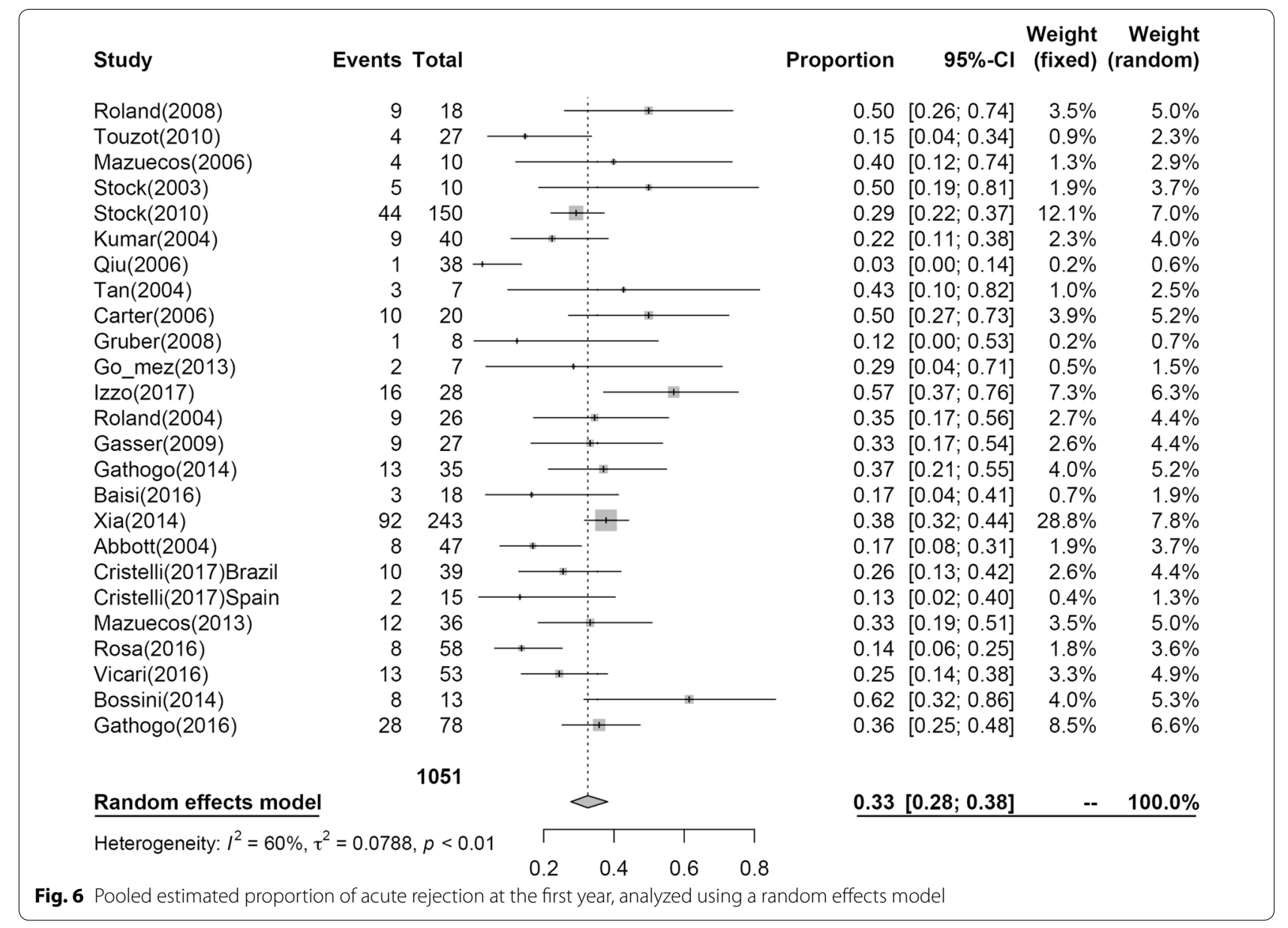

These findings suggest that although in current practice, $\mathrm{HIV}+$ candidates with pre-transplant CD4 counts between 200 and $349 / \mu \mathrm{L}$ are eligible for KT [26] and are likely to have outcomes similar to those with higher counts, this group of patients carries a substantial risk of lymphopenia and associated infections following ATG induction. 


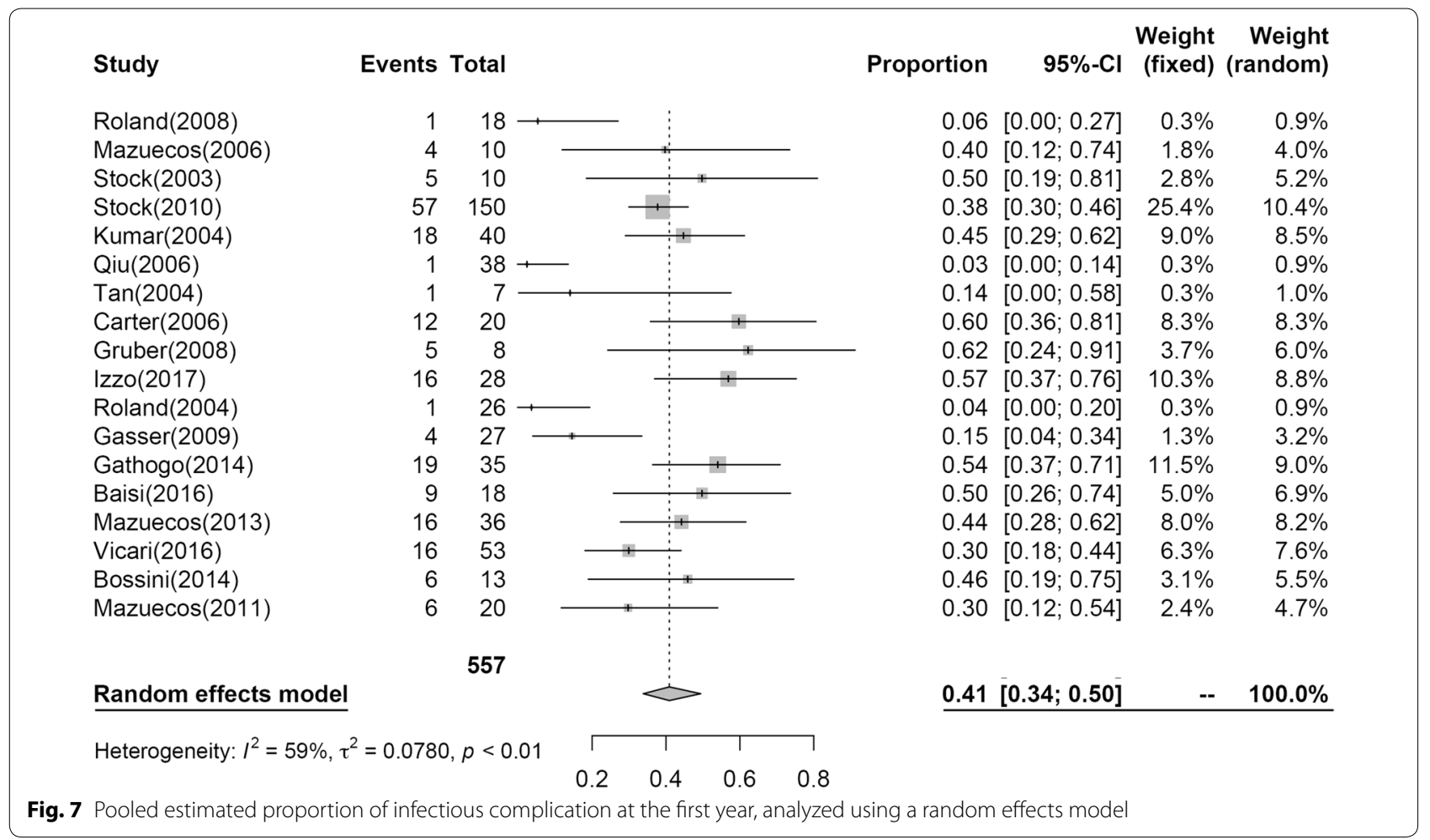

A study by Bossini et al. showed that in HIV+ KT recipients treated with basiliximab and maintained on a calcineurin inhibitor (CNI)-mycophenolic acid (MPA)based regimen, early corticosteroid withdrawal was associated with a very high incidence of AR and that kidney function was worse in patients with rejection [27].

However, in contrast to the studies above, in a large national cohort of $830 \mathrm{HIV}+\mathrm{KT}$ recipients, Kucirka found wide variation in the use of induction immunosuppression, with $>30 \%$ of HIV+ patients receiving no induction compared with only $20 \%$ of their HIV counterparts. Therefore, the study indicated that the use of induction, including the lymphocyte-depleting agent ATG, was not associated with an increased risk of infections. Despite the fact that induction recipients were at higher risk for $A R$, the researchers observed lower rates of delayed graft function (DGF), AR, graft loss and days spent hospitalized in the first year after KT as well as a trend towards lower mortality. They suggested that the benefits of induction immunosuppression to prevent graft rejection in HIV+ KT recipients far outweigh the perceived risk of increased infections. Because the study had the largest sample size to date and the cohort was nationally representative rather than a select study population, this study claims to be more credible. Furthermore, the authors accounted for confounding and treatment selection bias, which previous studies did not do, and they did this using inverse probability of treatment weighting (IPTW), a method that allowed them to adjust for many clinical and demographic factors even when modelling relatively rare outcomes such as graft loss and death [28].

\section{Acute rejection}

A high risk of AR is a well-known concern in HIVinfected kidney graft recipients. With regard to rejection, most studies observed a higher number of events in HIV+ patients than in HIV- patients. AR may occur as a result of immune dysregulation and the continuous inflammatory state of HIV+ recipients, in whom immunogenicity is increased following allograft implantation $[4,29]$.

Vicari et al. [30] evaluated the outcomes of KT in recipients with HIV infection under HAART in Brazil. The main results showed that HIV+ recipients presented a higher incidence of DGF, rejection, and bacterial infections and had lower PS and GS rates in comparison with a paired control group.

In the study, the incidence of treated AR was higher in the HIV+ group, and the incidence of biopsy-confirmed AR was numerically higher in this group. Additionally, even though an identical incidence of antibody-mediated AR occurred, the incidence of steroid-resistant rejection was numerically higher in the HIV group. Many reports 
have revealed an elevated incidence of $\mathrm{AR}$ in $\mathrm{HIV+}$ recipients, varying between $31 \%$ and $55 \%[4,9,10]$, although a significantly lower incidence was reported in one study [31]. Stock et al. [4] reported that a significant proportion of acute cellular rejections were steroid resistant and that no episodes of antibody-mediated AR were observed in their cohort.

However, Malat et al. [32] described an elevated incidence of mixed cellular and antibody-mediated rejections. Furthermore, Locke et al. [33] reported that HIV+ patients who received ATG induction therapy had a much lower risk of rejection compared to patients without induction and that the risk was similar to uninfected controls.

Gathogo et al. [34] reported that TAC has an impact in reducing the incidence of $\mathrm{AR}$ in $\mathrm{HIV}+$ recipients compared to cyclosporin A (CSA). The reasons for such an elevated incidence and severity of AR in HIV+ KT recipients are not clear. Dysregulation of the immune system along with a continuous inflammatory state caused by HIV infection, perhaps in association with a variability in drug exposure, has been hypothesized to explain these almost uniformly elevated incidences of rejection $[4,10$, 35].

In addition, the elevated incidence of acute cellular rejection has been recently hypothesized to partially occur a result of an infiltration of inflammatory cells that occurs in response to tubular cell infection by HIV [36].

A study by Malat showed a relatively higher incidence of mixed rejection in HIV+ recipients compared with that reported for non-HIV transplant recipients. A donor terminal serum creatinine greater than $2.5 \mathrm{mg} / \mathrm{dL}$ predicted mixed rejection and was associated with poor outcomes. Donor selection and optimization of immunosuppression may be critical in these patients [36]. Even if rejection was controlled successfully with steroid therapy, these results, as previously reported, suggest a possible scenario where the immune system, damaged by HIV infection, has a worse response to immunosuppressive treatment with respect to the general population, even in patients without a severe immunological dysfunction at the time of transplantation. In our analyses, AR at 1 year was 0.33 (95\% CI 0.28; 0.38).

\section{Infectious complications}

During the first decades of the renal transplantation era, a serious IC developed in up to $70 \%$ of patients following transplantation, resulting in fatal outcomes in as many as $11 \%$ to $40 \%$ of cases [37]. In a recent case-control study with a median follow-up of 5 years, Ailioaie et al. [38] found a similar incidence of post-transplant IC in HIV+ KT recipients compared with matched KT HIVcontrols. An IC incidence of $29 \%$ after transplantation was previously reported [19], and the incidence of posttransplant neoplasms has been described as similar to the incidence in HIV- patients. In our analyses, the incidence of IC observed at 1 year was $42 \%$ (95\% CI 0.34; $0.50, \mathrm{I}^{2}=59 \%$ ), and the rate of incidence of IC observed in this study in HIV+ KT patients is in line with the frequencies reported in a study by Stock et al. [4] where $38 \%$ of $150 \mathrm{HIV}-\mathrm{KT}$ recipients had at least one infection that required hospitalization.

However, the long-term patient and graft outcome of the whole cohort were not influenced by HIV status but were adversely influenced by infections, as survival was diminished in patients having at least one infection.

Furthermore, one-third of HIV+ KT recipients in a study by Ailioaie et al. did not have any episodes of infection, and repeated infections were not frequent. More importantly, the rate of incident infections was not different between the HIV+ and HIV - matched groups.

\section{Drug interaction}

As experience with transplantation in HIV+ patients grow, significant drug-drug interactions between ART and maintenance immunosuppression have been identified as a major clinical challenge.

Post-transplant management of HIV infection with protease inhibitor (PI) and nonnucleoside reverse transcriptase inhibitor (NNRTI)-based ART is complicated by reciprocal drug interactions with immunosuppressive therapy, especially CNI, because of inhibition or induction of P450 cytochrome enzymes. Co-administration of PIs with CNIs requires significantly decreased CNI doses and prolonged dosing intervals to avoid supratherapeutic trough levels.

Despite appropriate CNI dose adjustments, variations of drug serum levels are difficult to control and have been linked to increased graft rejection in HIV+ KT recipients [34, 39].

In a study of $150 \mathrm{HIV}+\mathrm{KT}$ patients, the largest to date, higher-than-expected rates of rejection were reported (31\% and $41 \%$ at 1 and 3 years, respectively) [4]. The authors speculated that increased rates of rejection may have been secondary to altered CNI levels since only one-third of patients on PI- or NNRTI-based regimens underwent CNI dose adjustments.

In a study by Rosa et al., patients receiving PI-containing regimens had lower PS at 1 and 3 years than patients receiving PI-sparing regimens $-85 \%$ vs. $100 \%(\mathrm{p}=0.06)$ and $82 \%$ vs. $100 \%(\mathrm{p}=0.03)$, respectively [40].

The increased risk of AR in HIV+ individuals has been largely attributed to reduced exposure to immunosuppressive agents due to drug-drug interactions with ART $[4,41,42]$. Other factors, such as infection of the 
allograft, previous alloimmunization and immune activation, might also play roles in predisposition to rejection [43].

This observation might be due to the effects of PI on tacrolimus levels, considering that the overwhelming majority of these patients were on a PI-containing regimen and that more than half had tacrolimus levels above target at the time of infection. PI could also influence the net state of immunosuppression by increasing the level or effect of other immunosuppressants, such as prednisone and mycophenolate.

The most important finding in the present study is the association between PI use and adverse outcomes, namely, reduced 3-year PS and GS, and increased risk of serious non-opportunistic infections. These observations remained true in analyses restricted to patients receiving nucleoside reverse transcriptase inhibitor (NRTI) "backbone"; thus, even after excluding the potential influence of other agents included in the ART regimen, PI continued to be associated with poor outcomes.

However, the use of NNRTI or tenofovir disoproxil fumarate (TDF) did not influence GS. Tenofovir alafenamide (TAF) is a new formulation of tenofovir associated with less kidney (and bone) toxicity [44]. Whether TAF has added clinical benefit over TDF in KT recipients remains to be established.

In a large single-centre study of HIV+ KT recipients conducted by Boyle et al. [45], treatment with TDF at the time of transplant was not associated with 36-month death-censored primary allograft loss after adjustment for DGF and a propensity score for TDF exposure.

Given that specific recipient characteristics, such as hepatitis B co-infection and certain HIV mutations, continue to make TDF-based regimens the most likely to provide adequate viral suppression post-transplant, despite observational data for nephrotoxicity in the nontransplant population.

However, given the limitations of this study, TDF should be reserved for patients who have limited ART options and should be used very cautiously in the KT population, with appropriate dose adjustment and surveillance of kidney function, including kidney biopsy when indicated. Substituting TAF for TDF in KT patients is reasonable, but it should be noted that no data are yet available on long-term kidney outcomes with TAF in KT and non-KT recipients in the setting of both preserved and reduced glomerular filtration rate (GFR).

Since their introduction in 2007, integrase strand transfer inhibitors (INSTIs) have been proposed as preferred post-transplant ART because of a favourable pharmacologic profile with decreased potential for drug interactions $[3,4,42,46]$. In a study by Stock et al. [4] the majority of patients were on PIs or NNRTIs with only $4 \%$ of participants receiving INSTIs; these patients were also receiving PI, NNRTI or maraviroc, making it impossible to draw conclusions about INSTI-based therapy. In a series of $27 \mathrm{HIV}+\mathrm{KT}$ patients in France predominantly on PI or NNRTI-based regimens (93\%), $70 \%$ required post-transplant ART modification due to drug interactions with CNIs [32].

Recently, Alfano et al., reported that preferred drug included raltegravir and dolutegravir for INSTI class, maraviroc for CCR5 receptor antagonist, lamivudine for NRTI, and rilpivirine for NNRTI, which offered advantage of having no drug interactions [47].

In summary, we believe that INSTI or CCR5-based therapy should be the preferred ART in patients with HIV who undergo KT, primarily because of decreased drug-drug interactions with immunosuppressive medications such as CNIs, enabling easier monitoring of immunosuppressive medications and superior graft outcomes. However, larger and more controlled trials are needed to better assess the long-term outcomes of INSTI-based therapy to elucidate factors related to GS other than direct reciprocal drug interactions.

\section{Conclusions}

In conclusion, this systematic review and meta-analysis demonstrated that with careful selection of patients and multidisciplinary evaluation, KT can be performed with good outcome in HIV+ patients. Moreover, with the advent of INSTI-based cART regimens, drug-drug interactions between cART and immunosuppressants have been dramatically reduced. Nevertheless, further studies are needed to optimize immunosuppressive therapy regimens for HIV+ patients, with the aim of reducing the high rate of AR after transplantation. Furthermore, this review still has its limitations, such as lack of sufficient studies, possibility of some overlapping patient cohorts, short of comparator. And we are also looking forward to other novel papers as more and more studies regarding KT of HIV+ patients.

\section{Abbreviations \\ HIV: human immunodeficiency virus; AIDS: Acquired Immune Deficiency Syndrome; HAART: highly active antiretroviral therapy; KT: kidney transplanta- tion; CART: antiretroviral combination therapy; ESRD: end-stage renal disease; CD4 counts: CD4 T cell counts; AR: acute rejection; PS: patient survival; GS: graft survival; IC: infectious complications; PRISMA: Preferred Reporting Items for Systematic Reviews and Meta-Analysis; NOS: Newcastle-Ottawa-Scale; ATG : antithymocyte globulin; CSA: cyclosporin A; MMF: mycophenolate mofetil; TAC: tacrolimus; MPA: mycophenolic acid; PI: protease inhibitor; DGF: delayed graft function; IPTW: inverse probability of treatment weighting; NNRTI: non- nucleoside reverse transcriptase inhibitor.}

Acknowledgements

Hao Tang assisted with the development of the search strategy. 


\section{Authors' contributions}

$X Z$ was a main contributor in the design, implementation and writing of the manuscript. XPH guided the study design and implementation. WRX independently assessed articles and extracted data independently. SZ, YX and $Y Z$ reviewed the articles. $L G$ contributed much in the revised version of our manuscript for updating the literature and revising the paper. So, LG was added as co-first author. All authors read and approved the final manuscript.

\section{Funding}

Not applicable.

\section{Availability of data and materials}

The datasets during and/or analysed during the current study available from the corresponding author on reasonable request.

\section{Ethics approval and consent to participate}

Not applicable.

\section{Consent for publication}

Not applicable.

\section{Competing interests}

The authors declare that they have no competing interests.

\section{Author details}

${ }^{1}$ Urology Institute, Capital Medical University, Beijing, China. ${ }^{2}$ Department of Urology, Beijing Chaoyang Hospital, Capital Medical University, 8 Gongti Nanlu, Chaoyang District, Beijing, China. ${ }^{3}$ Department of Urology, Beijing You-An Hospital, Capital Medical University, Beijing, China.

Received: 24 June 2019 Accepted: 9 November 2019 Published online: 20 November 2019

\section{References}

1. Swanson SJ, Kirk AD, Ko CW, Jones CA, Agodoa LY, Abbott KC. Impact of HIV seropositivity on graft and patient survival after cadaveric renal transplantation in the United States in the pre highly active antiretroviral therapy (HAART) era: an historical cohort analysis of the United States Renal Data System. Transplant Infect Dis. 2002;4(3):144-7.

2. Abbott KC. Human immunodeficiency virus infection and kidney transplantation in the era of highly active antiretroviral therapy and modern immunosuppression. J Am Soc Nephrol. 2004;15(6):1633-9.

3. Trullas JC, Cofan F, Tuset M, Ricart MJ, Brunet M, Cervera C, et al. Renal transplantation in HIV-infected patients: 2010 update. Kidney Int. 2011;79(8):825-42.

4. Stock PG, Barin B, Murphy B, Hanto D, Diego JM, Light J, et al. Outcomes of kidney transplantation in HIV-infected recipients. N Engl J Med. 2010;363(21):2004-14

5. Liberati A, Altman DG, Tetzlaff J, Mulrow C, Gotzsche PC, loannidis JP, et al. The PRISMA statement for reporting systematic reviews and meta-analyses of studies that evaluate healthcare interventions: explanation and elaboration. BMJ. 2009:339:b2700.

6. Stang A. Critical evaluation of the Newcastle-Ottawa scale for the assessment of the quality of nonrandomized studies in meta-analyses. Eur J Epidemiol. 2010;25(9):603-5.

7. DerSimonian R, Laird N. Meta-analysis in clinical trials. Control Clin Trials. 1986;7(3):177-88

8. Higgins JP, Thompson SG. Quantifying heterogeneity in a meta-analysis. Stat Med. 2002;21(11):1539-58.

9. Mazuecos A, Fernandez A, Andres A, Gomez E, Zarraga S, Burgos D, et al. HIV infection and renal transplantation. Nephrol Dial Transplant. 2011;26(4):1401-7.

10. Gathogo EN, Hamzah L, Hilton R, Marshall N, Ashley C, Harber M, et al. Kidney transplantation in HIV-positive adults: the UK experience. Int J STD AIDS. 2014;25(1):57-66.

11. Locke JE, Reed RD, Mehta SG, Durand C, Mannon RB, MacLennan P, et al. Center-level experience and kidney transplant outcomes in HIV-infected recipients. Am J Transplant. 2015;15(8):2096-104.
12. Palella FJ Jr, Baker RK, Moorman AC, Chmiel JS, Wood KC, Brooks JT, et al. Mortality in the highly active antiretroviral therapy era: changing causes of death and disease in the HIV outpatient study. J Acquir Immune Defic Syndr. 2006;43(1):27-34.

13. Friis-Moller N, Sabin CA, Weber R, d'Arminio Monforte A, El-Sadr WM, Reiss $P$, et al. Combination antiretroviral therapy and the risk of myocardial infarction. N Engl J Med. 2003;349(21):1993-2003.

14. Veenstra DL, Best JH, Hornberger J, Sullivan SD, Hricik DE. Incidence and long-term cost of steroid-related side effects after renal transplantation. Am J Kidney Dis. 1999;33(5):829-39.

15. Knight SR, Morris PJ. Steroid avoidance or withdrawal after renal transplantation increases the risk of acute rejection but decreases cardiovascular risk. A meta-analysis. Transplantation. 2010;89(1):1-14.

16. Locke JE, Mehta S, Reed RD, MacLennan P, Massie A, Nellore A, et al. A national study of outcomes among HIV-infected kidney transplant recipients. J Am Soc Nephrol. 2015;26(9):2222-9.

17. Izzo I, Casari S, Bossini N, Forleo MA, Sandrini S, Foca E, et al. Effectiveness of kidney transplantation in HIV-infected recipients under combination antiretroviral therapy: a single-cohort experience (Brescia, Northern Italy). Infection. 2018:46(1):77-82.

18. Morabito V, Grossi P, Lombardini L, Ricci A, Trapani S, Peritore D, et al. Solid organ transplantation in HIV+ recipients: Italian experience. Transplant Proc. 2016:48(2):424-30.

19. Landin L, Rodriguez-Perez JC, Garcia-Bello MA, Cavadas PC, Thione A, Nthumba $\mathrm{P}$, et al. Kidney transplants in HIV-positive recipients under HAART. A comprehensive review and meta-analysis of 12 series. Nephrol Dial Transplant. 2010;25(9):3106-15.

20. Xia Y, Friedmann P, Yaffe H, Phair J, Gupta A, Kayler LK. Effect of HCV, HIV and coinfection in kidney transplant recipients: mate kidney analyses. Am J Transplant. 2014;14(9):2037-47.

21. Cai J, Terasaki PI. Induction immunosuppression improves long-term graft and patient outcome in organ transplantation: an analysis of United Network for Organ Sharing registry data. Transplantation. 2010;90(12):1511-5.

22. Gabardi S, Martin ST, Roberts KL, Grafals M. Induction immunosuppressive therapies in renal transplantation. Am J Health Syst Pharm. 2011;68(3):211-8.

23. Kidney Disease: Improving Global Outcomes Transplant Work G. KDIGO clinical practice guideline for the care of kidney transplant recipients. Am J Transplant. 2009;9(Suppl 3):S1-155.

24. Weimer R, Ettrich M, Renner F, Dietrich H, Susal C, Deisz S, et al. ATG induction in renal transplant recipients: long-term hazard of severe infection is associated with long-term functional T cell impairment but not the ATG-induced CD4 cell decline. Hum Immunol. 2014;75(6):561-9.

25. Suarez JF, Rosa R, Lorio MA, Morris MI, Abbo LM, Simkins J, et al. Pretransplant CD4 count influences immune reconstitution and risk of infectious complications in human immunodeficiency virus-infected kidney allograft recipients. Am J Transplant. 2016;16(8):2463-72.

26. Ducloux D, Challier B, Saas P, Tiberghien P, Chalopin JM. CD4 cell lymphopenia and atherosclerosis in renal transplant recipients. J Am Soc Nephrol. 2003;14(3):767-72

27. Bossini N, Sandrini S, Casari S, Tardanico R, Maffeis R, Setti G, et al. Kidney transplantation in HIV-positive patients treated with a steroid-free immunosuppressive regimen. Transpl Int. 2014;27(10):1050-9.

28. Kucirka LM, Durand CM, Bae S, Avery RK, Locke JE, Orandi BJ, et al. Induction immunosuppression and clinical outcomes in kidney transplant recipients infected with human immunodeficiency virus. Am J Transplant. 2016:16(8):2368-76.

29. Trullas JC, Mocroft A, Cofan F, Tourret J, Moreno A, Bagnis Cl, et al. Dialysis and renal transplantation in HIV-infected patients: a European survey. J Acquir Immune Defic Syndr. 2010;55(5):582-9.

30. Vicari AR, Spuldaro F, Sandes-Freitas TV, Cristelli MP, Requião-Moura LR, Reusing JO, et al. Renal transplantation in human immunodeficiency virus-infected recipients: a case-control study from the Brazilian experience. Transplant Infect Dis. 2016;18(5):730-40.

31. Touzot M, Pillebout E, Matignon M, Tricot L, Viard JP, Rondeau E, et al. Renal transplantation in HIV-infected patients: the Paris experience. Am J Transplant. 2010;10(10):2263-9.

32. Malat GE, Ranganna KM, Sikalas N, Liu L, Jindal RM, Doyle A. High frequency of rejections in HIV-positive recipients of kidney transplantation: a single center prospective trial. Transplantation. 2012;94(10):1020-4. 
33. Locke JE, James NT, Mannon RB, Mehta SG, Pappas PG, Baddley JW, et al. Immunosuppression regimen and the risk of acute rejection in HIVinfected kidney transplant recipients. Transplantation. 2014;97(4):446-50.

34. Gathogo E, Harber M, Bhagani S, Levy J, Jones R, Hilton R, et al. Impact of tacrolimus compared with cyclosporin on the incidence of acute allograft rejection in human immunodeficiency virus-positive kidney transplant recipients. Transplantation. 2016;100(4):871-8.

35. Frassetto L, Floren L, Barin B, Browne M, Wolfe A, Roland M, et al. Changes in clearance, volume and bioavailability of immunosuppressants when given with HAART in HIV-1 infected liver and kidney transplant recipients. Biopharm Drug Dispos. 2013;34(8):442-51.

36. Canaud G, Dejucq-Rainsford N, Avettand-Fenoel V, Viard JP, Anglicheau D, Bienaime $F$, et al. The kidney as a reservoir for HIV-1 after renal transplantation. J Am Soc Nephrol. 2014;25(2):407-19.

37. Khoury JA, Brennan DC. Infectious complications in kidney transplant recipients: review of the literature. Saudi J Kidney Dis Transpl. 2005; 16:453-97.

38. Ailioaie O, Arzouk N, Valantin MA, Tourret J, Calin RO, Turinici M, et al. Infectious complications in HIV-infected kidney transplant recipients. Int J STD AIDS. 2018;29(4):341-9.

39. Yoon SC, Hurst FP, Jindal RM, George SA, Neff RT, Agodoa LY, et al. Trends in renal transplantation in patients with human immunodeficiency virus infection: an analysis of the United States renal data system. Transplantation. 2011;91(8):864-8.

40. Rosa R, Suarez JF, Lorio MA, Morris MI, Abbo LM, Simkins J, et al. Impact of antiretroviral therapy on clinical outcomes in HIV (+) kidney transplant recipients: review of 58 cases. F1000Res. 2016;5:2893.

41. Stock PG. Kidney infection with HIV-1 following kidney transplantation. J Am Soc Nephrol. 2014;25(2):212-5.

42. Tricot L, Teicher E, Peytavin G, Zucman D, Conti F, Calmus Y, et al. Safety and efficacy of raltegravir in HIV-infected transplant patients cotreated with immunosuppressive drugs. Am J Transplant. 2009;9(8):1946-52.

43. Lorio MA, Rosa R, Suarez JF, Ruiz P, Ciancio G, Burke GW, et al. Influence of immune activation on the risk of allograft rejection in human immunodeficiency virus-infected kidney transplant recipients. Transpl Immunol. 2016:38:40-3.

44. Wang H, Lu X, Yang $X, X u$ N. The efficacy and safety of tenofovir alafenamide versus tenofovir disoproxil fumarate in antiretroviral regimens for HIV-1 therapy: meta-analysis. Medicine (Baltimore). 2016;95(41):e5146.

45. Boyle SM, Malat G, Harhay MN, Lee DH, Pang L, Talluri S, et al. Association of tenofovir disoproxil fumarate with primary allograft survival in HIVpositive kidney transplant recipients. Transplant Infect Dis. 2017;19:4.

46. van Maarseveen EM, Rogers CC, Trofe-Clark J, van Zuilen AD, Mudrikova T. Drug-drug interactions between antiretroviral and immunosuppressive agents in HIV-infected patients after solid organ transplantation: a review. AIDS Patient Care STDS. 2012;26(10):568-81.

47. Alfano G, Mori G, Fontana F, Dolci G, Baisi A, Ligabue G, Ferrari A, Solazzo A, Franceschini E, Guaradi G, Mussini C, Cappelli G. Int J STD AIDS. 2018;29(13):1305-15 (Epub 2018 Jul 10).

48. Roland ME, Barin B, Carlson L, Frassetto LA, Terrault NA, Hirose R, et al. HIVinfected liver and kidney transplant recipients: 1- and 3-year outcomes. Am J Transplant. 2008;8(2):355-65.
49. Mazuecos A Pascual J Gomez E Sola E Cofan F Lopez F et al. Renal transplantation in HIV-infected patients in Spain. Nefrologia. 2006:26(1):113-20.

50. Stock PG, Roland ME, Carlson L, Freise CE, Roberts JP, Hirose R, et al. Kidney and liver transplantation in human immunodeficiency virusinfected patients: a pilot safety and efficacy study. Transplantation. 2003;76(2):370-5.

51. Kumar MS, Sierka DR, Damask AM, Fyfe B, McAlack RF, Heifets M, et al. Safety and success of kidney transplantation and concomitant immunosuppression in HIV-positive patients. Kidney Int. 2005;67(4):1622-9.

52. Qiu J, Terasaki PI, Waki K, Cai J, Gjertson DW. HIV-positive renal recipients can achieve survival rates similar to those of HIV-negative patients. Transplantation. 2006;81(12):1658-61.

53. Tan HP, Kaczorowski DJ, Basu A, Khan A, McCauley J, Marcos A, et al. Living-related donor renal transplantation in HIV+ recipients using alemtuzumab preconditioning and steroid-free tacrolimus monotherapy: a single center preliminary experience. Transplantation. 2004;78(11):1683-8.

54. Carter JT, Melcher ML, Carlson LL, Roland ME, Stock PG. Thymoglobulinassociated $\mathrm{Cd} 4+\mathrm{T}$-cell depletion and infection risk in HIV-infected renal transplant recipients. Am J Transplant. 2006;6(4):753-60.

55. Gruber SA, Doshi MD, Cincotta E, Brown KL, Singh A, Morawski K, et al. Preliminary experience with renal transplantation in HIV+ recipients: Iow acute rejection and infection rates. Transplantation. 2008;86(2):269-74.

56. Gomez V, Fernandez A, Galeano C, Oliva J, Diez V, Bueno C, et al. Renal transplantation in HIV-infected patients: experience at a tertiary hospital in Spain and review of the literature. Transplant Proc. 2013:45(3):1255-9.

57. Roland ME. Solid-organ transplantation in HIV-infected patients in the potent antiretroviral therapy era. Top HIV Med. 2004;12(3):73-6.

58. Gasser O, Bihl F, Sanghavi S, Rinaldo C, Rowe D, Hess C, et al. Treatmentdependent loss of polyfunctional CD8+T-cell responses in HIV-infected kidney transplant recipients is associated with herpesvirus reactivation. Am J Transplant. 2009;9(4):794-803.

59. Baisi A, Nava F, Baisi B, Rubbiani E, Guaraldi G, Di Benedetto F, et al. Kidney transplantation in HIV-infected recipients: therapeutic strategy and outcomes in monocentric experience. Transplant Proc. 2016;48(2):333-6.

60. Cristelli MP, Cofán F, Tedesco-Silva H, Trullàs JC, Santos DWCL, Manzardo $C$, et al. Regional differences in the management and outcome of kidney transplantation in patients with human immunodeficiency virus infection: a 3-year retrospective cohort study. Transplant Infect Dis. 2017;19:4

61. Mazuecos A, Fernandez A, Zarraga S, Andres A, Rodriguez-Benot A, Jimenez $C$, et al. High incidence of delayed graft function in HIV-infected kidney transplant recipients. Transpl Int. 2013;26(9):893-902.

62. Malat GE, Boyle SM, Jindal RM, Guy S, Xiao G, Harhay MN, et al. Kidney transplantation in HIV-positive patients: a single-center, 16-year experience. Am J Kidney Dis. 2019;73(1):112-8.

\section{Publisher's Note}

Springer Nature remains neutral with regard to jurisdictional claims in published maps and institutional affiliations.

Ready to submit your research? Choose BMC and benefit from

- fast, convenient online submission

- thorough peer review by experienced researchers in your field

- rapid publication on acceptance

- support for research data, including large and complex data types

- gold Open Access which fosters wider collaboration and increased citations

- maximum visibility for your research: over 100M website views per year

At BMC, research is always in progress.

Learn more biomedcentral.com/submissions 